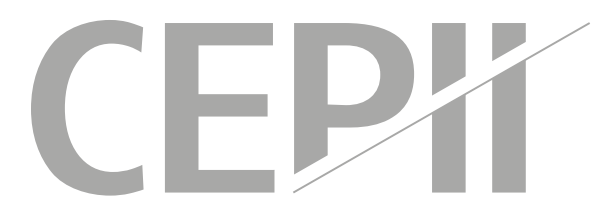

\title{
Information in the First Globalization: News Agencies and Trade
}

Pierre Cotterlaz \& Etienne Fize

Highlights

- We document the effect on international trade of a reduction in information frictions.

- We use the emergence of global news agencies in the XIXth century, that collected and sold news abroad.

- Trade between two countries increases significantly when these two countries are covered by a news agency. 


\section{Abstract}

This paper documents the effect of information frictions on trade using a historical large-scale improvement in the transmission of news: the emergence of global news agencies. The information available to potential traders became more abundant, was delivered faster and at a cheaper price between countries covered by a news agency. Exploiting differences in the timing of telegraph openings and news agency coverage across pairs of countries, we are able to disentangle the pure effect of information from the effect of a reduction in communication costs. Panel gravity estimates reveal that bilateral trade increased by $301 \%$ more for pairs of countries covered by a news agency and connected by a telegraph than for pairs of countries simply connected by a telegraph.

\section{Keywords}

Information, International Trade, Economic History, News Agency, First Globalization.

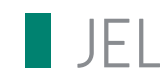

N70, F14, F15, F10.

\section{Working Paper}

CEPII (Centre d'Etudes Prospectives et d'Informations Internationales) is a French institute dedicated to producing independent, policyoriented economic research helpful to understand the international economic environment and challenges in the areas of trade policy, competitiveness, macroeconomics, international finance and growth.

CEPII Working Paper
Contributing to research in international
economics
@ CEPII, PARIS, 2021
All rights reserved. Opinions expressed
in this publication are those of the
author(s) alone.

Editorial Director: Sébastien Jean

Production: Laure Boivin

Published on 15.02.21

No ISSN: $1293-2574$
CEPII

20, avenue de Ségur TSA 10726 +33153685500 www.cepii.fr Press contact: presse@cepii.fr 75334 Paris Cedex 07 


\section{Introduction}

Over the course of the XIXth century, international trade flows experienced an unprecedented rise. Recent contributions (Steinwender 2018; Juhász and Steinwender 2018) highlighted the key role of the telegraph in explaining this "First Globalization" (on top of the "usual suspects", namely changes in trade policy and lower transport $\left.\operatorname{costs}^{1}\right)$. However, an improvement in the communication technology, such as the one studied in these papers, could affect international trade through two channels. Firstly, it reduces search frictions: it's less costly to find buyers or sellers for a specific product, and to coordinate with them. Secondly, it increases the quantity and quality of information available to potential traders. This information channel seems to have been overlooked by the literature, despite its expected relevance as a determinant of export and import decisions: for the exporters, knowledge of the foreign market characteristics (market size, price, trade costs, demand shifters) is of prime importance, while for the importers, the sourcing choice is determined by the information available on price and quality from different markets.

The specific context of the XIXth century provides a unique opportunity to disentangle the two abovedescribed mechanisms. Indeed, this period witnessed the birth of global news agencies, which systematically collected and transmitted information across borders, so that, for the first time, news became widely available from almost all parts of the globe, with sharply reduced delays. News agencies are wholesalers of information: they gather news and sell them to governments, businesses, and newspapers. ${ }^{2}$ On top of more conventional subjects such as diplomacy and politics, providing their customers with commercial news was an important part of the business model of these news agencies. Moreover, the three largest news agencies quickly syndicated into an efficient cost-sharing organization: each of them was given a monopoly over a set of countries, and in exchange committed to share information on these countries with the other news agencies. The sharing of information among the three global news agencies was truthfully enforced, since it ensured that they would stay ahead of the competition. Therefore, being covered by a global news agency meant becoming part of an international network of news sharing, including commercial news.

The development of international news agencies was deeply intertwined with the construction of an international telegraph network: news agencies relied on the telegraph to communicate and often contributed to its expansion. The telegraph represented a considerable improvement upon previous communication technologies, ${ }^{3}$ allowing for shorter and less volatile transmission delays. Even though it made communications easier, it did not provide a centralized and reliable source of business information. Indeed, telegraphic messages were private, and it was therefore possible to restrict access to some chosen users. On the other hand, news agencies collected, gathered and sold information that could then be accessed by anyone at a low cost: the end of XIXth century was the period of penny papers and mass media consumption. In other

\footnotetext{
${ }^{1}$ See for instance Estevadeordal et al. (2003) and Pascali (2017).

${ }^{2}$ Newspapers were the main channel of information at the time, they became widely available, and relatively cheap, so that any information published in a newspaper can be considered as public information. In the very competitive environment that prevailed on the press market, it would have been too expensive for these numerous newspapers to collect news from abroad on their own, so they had to rely on news agencies to obtain these news.

${ }^{3}$ Before the invention of the telegraph, mail had to be transported carrying on steamships, railways or horses, which in some situations implied months of delay.
} 
words, in the absence of a global news agency, telegraphs reduced only the communication frictions, without much effect on the amount of information available to the public. We use this distinction between easily enforceable restrictions of access on the telegraph communications and the quasi-public nature of newspaper information to disentangle the effects of reduced communication costs from the effects of improved information access, a separation that previous studies were unable to make.

The telegraph and the news agencies did not cover all pairs of countries simultaneously. The success of the telegraph was immediate, but the cost of the infrastructure and technical factors implied that not all the countries could be quickly connected. Similarly, the global news agencies did not expand their operations to the entire world immediately. They started by sharing Europe and then gradually increased the scope of their syndication agreement through contracts struck in 1859, 1867, 1876, 1889 and 1902. This sequential entry of country pairs into the telegraph and news agencies networks is key for our identification strategy, because it allows us to estimate a panel data version of the gravity equation, meaning that on top of the usual origin and destination time varying fixed effects, we can include country-pair fixed effects, which control for any time-unvarying characteristic of the two countries.

News agencies collected and sold information in a country based on the expected profits from serving this country, which in turn may be related to future trade flows. To alleviate the concerns arising from this situation, we use the inclusion of the country into the global news agencies syndication agreement as our measure of news agency coverage. We argue that it accurately reflects the entry in the global news sharing network, since it creates a clear incentive for a global news agency to start covering the country: before being granted exclusivity on a market, a global news agency could decide to sell and collect news, but the exploitation was less likely to be profitable in a competitive situation than in an organized monopoly. Moreover, the extensions of the agreement never concerned one single country, they always included groups of countries, usually of the same geographic region, which suggests that the date of entry into the agreement had more to do with negotiations between the news agencies than with expected trade flows, and that many countries started being covered as a by-product of the agreement rather than for their anticipated economic importance.

Our approach to capture the effect of the information channel is therefore to focus on the interaction between telegraph connections and news agency coverage: while the effect of the telegraph alone can be attributed to the sole decrease in communication costs, the interacted term specifically isolates the contribution of an improved access to news between the two covered countries. We find that trade flows increase by $40 \%$ when two countries become connected by a telegraph. When they are covered by a news agency and connected by a telegraph, the value of trade flows increases by an additional $30 \%$. News agencies, in the absence of telegraph, do not trigger any significant increase in trade, suggesting that they were unable to operate at full efficiency when an appropriate communication technology was not available.

These results hold when we control for colonial ties, and data on French tariffs suggest that they are not driven by correlated changes in trade policy. Moreover, we use indirect connections as sources of plausibly more exogenous variations in our explanatory variables. For country pairs that became indirectly linked after the opening of a telegraph line, as for instance Chile and Egypt in 1874, the timing of opening is unlikely 
to be related to bilateral expected trade flows. Similarly, for the news agencies, if potential traders lobby to include some countries in the cartel agreement based on a perceived high trade potential, it should mostly happen in country pairs in which one of the countries is the headquarter of the news agency, since it is easier to influence a domestic firm than a foreign one. Coverage of other country pairs, as for instance Argentina and New-Zealand in 1876, can be seen as an unintended by-product of the expansion. Leaving aside the direct telegraph connections and the country pairs where one country hosts the headquarter of the news agency, we still find a significant positive trade effect of the interaction between news agency and telegraph.

We then analyze the time dynamics of the effect through an event-study, and find a progressive increase in its magnitude, which slowly rises up to thirty years after the dyads are connected, a picture consistent with a slow constitution of business networks between the countries that benefited from an improved access to information on each others. Finally, we provide evidence supporting the hypothesis that the trade effect is indeed driven by an increase in the quantity of information available on foreign countries. First, we document an increase in trade volatility after the connection, in line with the findings of Steinwender (2018). This is consistent with a better ability of traders to adapt to market conditions. Second, using data on French newspapers, we find an increase in the presence of a country in the articles once this country benefits from a telegraph connection and from a news agency coverage.

This paper builds on a large literature documenting the effect of information frictions on various economic outcomes, starting with a reduction in price dispersion (Jensen 2007; Ejrnæs and Persson 2010). Linking this literature with international trade, T. Allen (2014) shows that, on top of the usual effect on price dispersion, a decrease in information frictions positively affects the volume of trade. More recent approaches to incorporate information frictions in trade models include Dasgupta and Mondria (2018) and Lenoir et al. (2020). Empirically, the prediction of an increase in trade flows after a decrease in communication costs is established by Malgouyres et al. (2019), who make use of the sequential arrival of high speed internet in French cities. Unlike our approach, these papers however think of information frictions either as search costs or as a mixture of search costs and constrained information set, and do not attempt to distinguish these two dimensions.

The literature recently started emphasizing the importance of the information set available to the firm in explaining export decisions. Indeed, these decisions crucially rely on the expectation the firm forms about the profits it will earn by serving the foreign market. While perfect foresight is commonly assumed (firms perfectly predict the profits from exporting), Dickstein and Morales (2018) acknowledge that firms actually use only a restricted set of observable variables to assess their expected profits, and study the consequences of enlarging this set of variables. Consistently with our results, they find that more information results in more exports.

Our results complement the work of Juhász and Steinwender (2018), who document an increase in trade flows following the opening of telegraph lines, especially for goods whose characteristics are easily codifiable, hinting to the fact that communications costs indeed decreased. Our results are also consistent with Steinwender (2018), who describe the positive effect of the transatlantic telegraph on price convergence 
and adaptation to demand shocks in the cotton market, mentioning the importance of the "Reuter's telegram" provided to traders in the exchanges. However, she cannot separate the contribution of these telegrams from other communications allowed by the telegraph. Moreover, the larger span of our dataset (worldwide trade flows) allows to further control for potential endogeneity, for instance by separating direct and indirect connections.

The importance of the press as a vector of public information is not new in the literature. However, to our knowledge, there is no previous work on the importance of news agencies as providers of valuable economic information. The literature on news agencies has focused on industrial organization aspects of the news agencies syndication agreement. Wolff (1991) describes the historical evolution of the news agency industry. Bakker (2014) explains how their business model was designed to answer the specificity of the news market: it provided a solution to the Arrow information paradox (buyers want to know the information in order to determine how much they are willing to pay, but once the information is revealed, they don't need to pay anymore).

In the next section, we present the historical context of our analysis, and our data. Section 3 details our main results, followed by some robustness checks in section 4 . In section 5 , we provide evidence that the effect we find can indeed be attributed to an increase in the circulation of information.

\section{Context and data}

\subsection{Context}

The creation of an international telegraph network The first telegraph system implemented at a significant scale is the optical telegraph of Claude Chappe, which used blades or paddles to transmit information between towers (semaphore telegraph). It was mostly adopted in France where, in the first half of the XIXth century, all major cities were linked together, but had little commercial use and international connections. This is why we focus on the electrical telegraph, that appeared in the $1830 \mathrm{~s} .{ }^{4}$, and quickly became the dominant communication technology, as witnessed by the spectacular growth of the network, both domestically ${ }^{5}$ and internationally. The total length of telegraphic wires reached 7 millions $\mathrm{km}$ in 1913, and the number of messages exchanged followed a similar pattern, rising sharply from 28 millions telegrams sent in 1865 to 528 millions in 1913.

For long-distance lines, the preferred technology was the submarine cable, because it avoided having to negotiate with countries crossed by the line. The first successful international submarine cable linked France and the UK in 1851. Governments quickly recognized the importance of the telegraph for international communications and soon started cooperating within multinational instances: the German-Austrian Telegraph Union in 1851, the Western European Telegraph Union in 1855, and finally the International Telecommunication Union (ITU) in 1865, that still operates today as a UN agency. International conven-

\footnotetext{
${ }^{4}$ The first functioning line, by Cooke and Wheatstone, was built in 1839 between London and a suburbs town.

${ }^{5}$ For instance, in France, the length of the domestic telegraph network was $3540 \mathrm{~km}$ in 1852 and $42986 \mathrm{~km}$ in 1870.
} 
tions were adopted to ensure the smoothness of transmissions. For instance, in 1865, the Morse code was chosen for all international communications.

The telegraph was a major improvement upon the former communication technologies. It was therefore immediately adopted by private agents to conduct their business operations, as highlighted by Wenzlhuemer (2013, p.84): "from its very inception, the telegraph was intimately connected with the world of business, finance and trade". Nevertheless, its use was very expensive, and therefore reserved to wealthy individuals and firms, governments, and news agencies.

The rise of global news agencies The emergence of news agencies is intimately linked to the sharp rise in newspapers diffusion, that made the press the dominant channel of information at the time. The first news agency appeared in 1832 and was named after its creator, Charles-Louis Havas. The success of Havas, which quickly established a monopoly on its domestic market (France) ${ }^{6}$ and started expanding its activity to foreign markets, triggered the creation of competing news agencies. Two former Havas employees, Bernhard Wolff and Paul Julius Reuter, started their own business, creating respectively the Wolffs Telegraphisches Bureau (1849) in Germany (henceforth referred to as "Wolff") and Reuters (1851) in the UK, which quickly gained contracts with newspapers outside of their domestic market. In the $1850 \mathrm{~s}$, the market for international news is therefore an oligopoly with three major players : Havas, Reuters and Wolff. These three incumbents quickly understood that more profit could be made by colluding, i.e. by avoiding duplicate costs of news production in some countries, and avoiding competition in some markets. This led to the birth of the international news cartel in 1859.

The main component of the 1859 agreement is that each agency was granted a monopoly position in some countries, meaning that no competitor could sell news to the press (or to local news agencies) in these countries. For instance, Havas was the only agency allowed to sell news in Spain, Reuters and Wolff agreed to voluntarily restrain from contracting in this country. However, a key dimension of the agreement is that the news agencies committed to share without fees information coming from their exclusivity zone. Coming back to the Spanish example, this means that Havas had to send the news coming from Spain to the two other cartel members. Moreover, to prevent the appearance of any serious competitor, the three colluding news agencies agreed to communicate only with each other, they could not sell news to another competing news agency. Finally, they pledged to develop the telegraphic infrastructure.

This first agreement mostly concerned only European territories, the rest of the world remained fair game. News agencies were free to collect and sell information in the neutral territories, but there was no systematic exchange of information between them for these territories. But over time, the agreement was reshaped to incorporate new markets that the news agencies deemed profitable. The main extensions occurred in 1867, 1876, 1889 and 1902. On each occasion, new countries were added to the cartel. Table 5 (in the appendix) indicates the countries that were added by each cartel agreement. Additionally, two news agencies joined the cartel: AP in 1876 and the Korrbureau in 1889. The cartel slowly dislocated in

\footnotetext{
${ }^{6}$ In 1860, 9 out of 10 Parisian newspapers were subscribers of the French international news agency Havas and for almost all of them it was the most important source of content (Martin 1997).
} 
the aftermath of WWI. After the conflict, Wolff lost its territories, which were shared between the still highly cooperative duo Reuters-Havas. But AP and the other US news agencies (United Press and International News Service) put more pressure on the historic European duo. In the 1927 cartel agreement, many countries became shared territories. The early 1930s were the final blow to the cartel, which officially ceased to operate in 1934. Nowadays, the market is still an oligopoly, with Reuters and AP by far the biggest players and AFP (former Havas) as the third player.

With the news agency cartel, for the first time, a systematic collection and transmission of information across countries is in place. Even though the cartel reduced competition in each local market, it made the coverage of the country profitable (G. Allen 2013; Bakker 2014). The cartel organization also implied a level of information sharing across the global news agencies that arguably would not have been reached under a more competitive system. Indeed, news agencies really shared the news collected in their exclusive geographical areas. In some cases cooperation was even higher, Reuters and Havas entered into a jointpurse agreement in 1870. According to Bakker (2014) and G. Allen (2013), this organization allowed for an increase in the coverage area, quality and quantity of information. The formal inclusion in the cartel matters since, even though a neutral territory could be served by a news agency, this situation was unlikely given that the market was less likely to be profitable.

It is important to keep in mind that the news agencies were private businesses, under no government mandate. Even though there may have been pressures from their domestic governments, especially during periods of conflict, profit maximization remained their primary objective. As none of the news agencies was State-owned, the decision to add a country in the cartel was not directly taken by governments. This does not mean that countries are added independently from diplomatic or economic considerations, but it implies that the costs and benefits for the news agency is likely to be a key driver of the decision. The case of South-America is a particularly good example: South-America, at the time more economically and politically linked to Great-Britain, was given to Havas to compensate for Reuters getting large territories in Asia.

Figure 1: Extract from The Morning Post, 02/29/1892

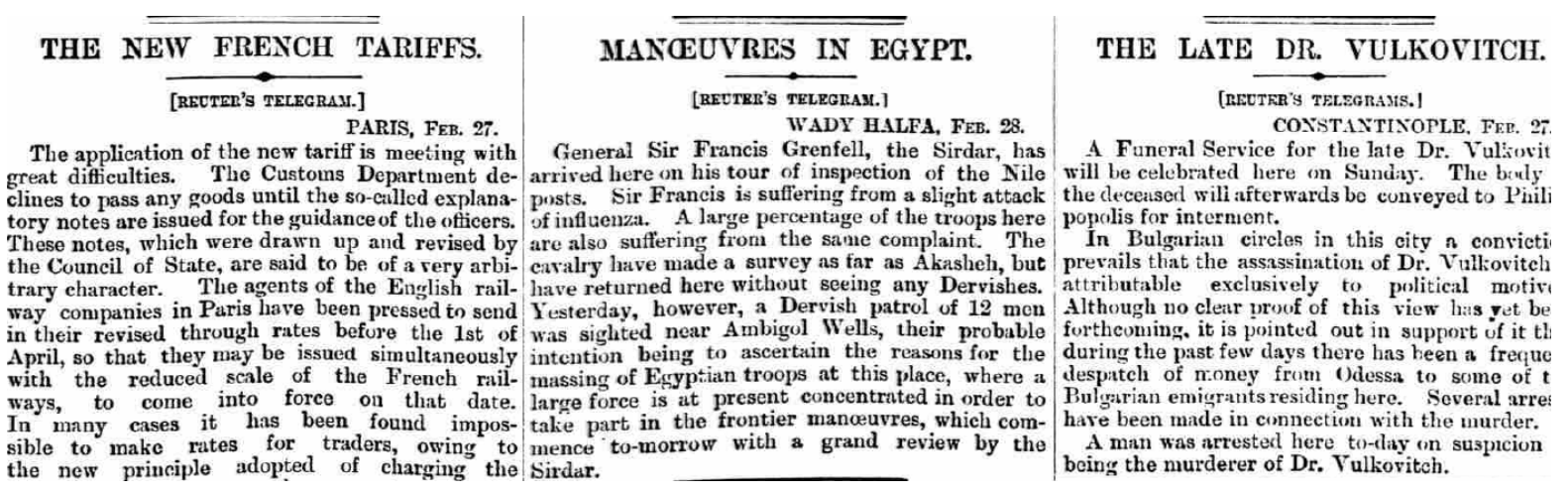

News are available from all around the world through the "Reuter's telegrams", including from a country that is not part of Reuters' exclusive distribution area (France). Source: British Newspaper Archive. 
As figure 1 illustrates, newspapers used the global news agencies as their main, and often sole, source of foreign information. Indeed, it was too costly for each newspaper to collect foreign news on its own. ${ }^{7}$ They could either be direct subscribers to the international news agencies services, or clients of a national news agency which in turn relied on a global news agencies for foreign news. Government or private organizations could also subscribe to foreign news services from the global news agency serving their country.

News agencies and telegraph complement each other The reduction in information friction is fully realized when two countries are both covered by a news agency and linked by a telegraph. In the absence of a telegraph line, news agencies do not have the possibility to send news swiftly from one country to another. Conversely, in the absence of news agencies, information can flow among privileged users, but not systematically and with the large audience reached by the newspapers.

Because the telegraph was at the core of the news agency operations, the geographic extensions of the cartel coincided with the development of the telegraph network. The motto of Paul Julius Reuter was clear: "Follow the cable". 8 The cartel started by dividing Europe where the telegraph network was quite dense. Then South America and Australia were included in 1876, a few years after being linked to Europe by submarine cables (in 1874 for South America and 1872 for Australia). It does not however imply that all countries added to the cartel were already connected by a telegraph. ${ }^{9}$ The telegraph provided the speed, reliability and privacy necessary to the news agencies. The link between news agencies an the telegraph is so tight that they were often referred to as "telegraphic news agencies", and sometimes even played an active role in the construction of new telegraph lines. ${ }^{10}$

Without the news agencies, a systematic and efficient transmission of information cannot take place, and the impact of the telegraph is restricted to its use as a communication device for those that can afford it. Indeed, sending telegrams was very expensive ${ }^{11}$ and therefore de facto reserved to the most important and well established traders, while the press was relatively cheap and accessible to any potential trader. The role of newspapers as provider of public information is explicitly acknowledged by Ejrnæs and Persson (2010): "A flourishing commercial press turned what used to be exclusively or privately held knowledge into publicly accessible information. While the larger merchants' houses had access to telegraph transmission directly, others relied on 'cable news' reported in the press."

In fine, thanks to the telegraph, news agencies were able to transmit information considerably faster than before, especially for very distant countries. In figure 2, we plot the average delay between the date of

\footnotetext{
${ }^{7}$ Even though a handful of newspapers had foreign correspondents in some specific locations for which they believed their readership would ask for very detailed reports, the cost was too high for this practice to be common. Only a few newspapers could afford foreign correspondents and these correspondents were often sent temporarily to cover big events (Albert 2010).

${ }^{8}$ Wenzlhuemer (2013, p. 90)

${ }^{9}$ Bolivia and Ecuador for instance were not connected to any international telegraph in 1876.

${ }^{10}$ For instance, the transatlantic telegraph was built with the guarantee by Reuters to bring a "considerable volume of business" (Unesco 1952, p.153.), and Bielsa (2008) explains that news agencies "have been instrumental in the creation of the material infrastructures for the production and circulation of information and in the development of worldwide networks, starting with the telegraph, which, in the second half of the nineteenth century became the first system for global communications"

${ }^{11}$ For instance sending a 10 word transatlantic telegram in 1866 corresponded one fifth of the annual wage of a US skilled worker.
} 
Figure 2: Delay between the date of an event and its publication in the Time (London)

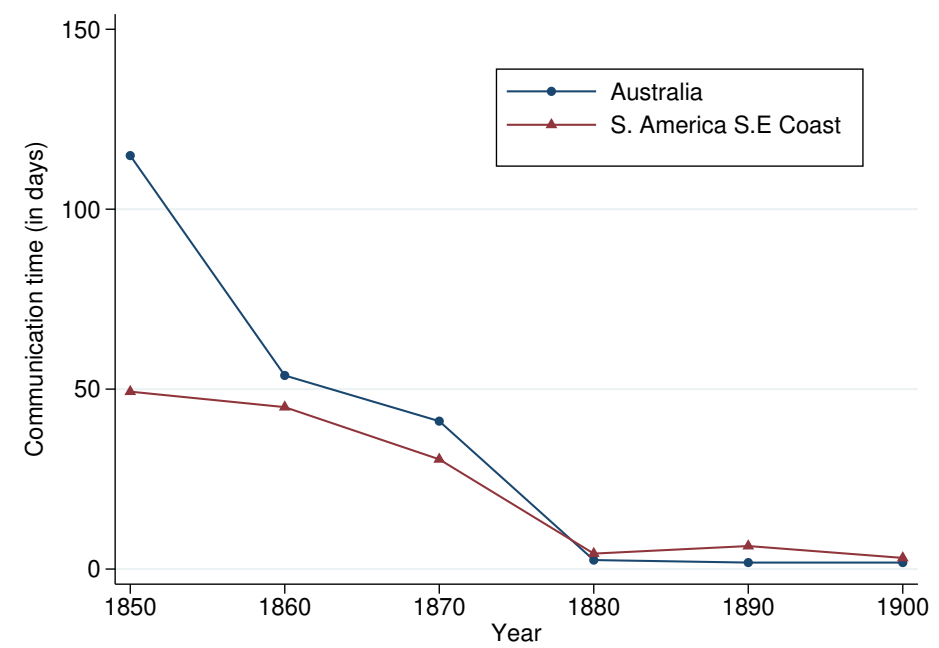

$y$-axis : average number of days between the date an event took place and the date it was reported in the Time (London). Data source : Wenzlhuemer (2013)

an event and the date of publication of this event in the Time, a London newspaper. The dramatic drop in transmission times between London and South America coincides with the opening of the 1874 telegraph between Europe and South America. Australia was finally connected with Europe in 1872. Both South America and Australia entered the coverage of news agencies in 1876. From 1880 onwards, information is shared within days, compared with months a few decades ago.

\subsection{Data}

Trade data: Information on historical bilateral trade flows comes from the TRADHIST database (Fouquin and Hugot 2016), which combines data from previous databases with novel information extracted from primary sources (manuscripts from the customs archives). It also contains several bilateral variables linked to trade frictions, such as distance. On top of its extensive coverage of past trade flows, TRADHIST has the desirable feature that it gives preference to importer reported data, when available, which ensures higher accuracy. We nevertheless had to make two substantial modifications to the original data. First, because our analysis relies heavily on time variation, it was crucial to ensure consistency over time of the countries, so we grouped them according to the largest existing legal entity over the period. For instance, Sweden and Norway formed a single Kingdom until 1905, at which point Norway became an independent country, so we gathered them into a single entity, "Sweden-Norway". We obtained the trade flows of the so-formed entities by summing the trade flows of their components: trade flows between "Sweden-Norway" and Denmark after 1905 are the sum of trade flows between Sweden and Denmark, and trade flows between Norway and 
Denmark. Second, we re-coded the variables indicating bilateral colonial ties to ensure higher accuracy.

Our analysis starts in 1850, nine years prior to the first cartel agreement (1859) and fifteen years after the creation of the first news agency (Havas, 1835). It ends in 1914, since World War I is known to have significantly disrupted the trade patterns, and the cartel agreements were de facto less binding after 1918, even though they still formally existed. Over this period (1850-1914), five cartel agreements were struck : in 1859, 1867, 1876, 1889 and 1902. Our baseline unit of analysis is a directed pair of countries, i.e. a combination importer-exporter (France -> Uruguay for instance). Throughout the paper, we often refer to these pairs of countries as dyads. The country of origin is indexed by $o$, and the destination country by $d$.

News agency data: We hand-coded the geographic coverage of the news agency cartel based on information provided in Wolff (1991). More precisely, we defined a dummy variable NewsAgenc $y_{\text {odt }}$ taking value 1 when the importer and the exporter are covered by a news agency participating to the international news exchange agreements. This bilateral variable is not directed: if NewsAgency $y_{o d t}=1$, then $N A_{d o t}=1$. Colonies are not systematically mentioned in the cartel agreements, so that it's hard to tell whether they were actually covered by a news agency or not. Therefore, in our baseline specification, we adopt the conservative approach of setting our NA dummy to 1 only for countries whose status is explicitly stated in Wolff (1991). In figure 3, we plot the number of countries mentioned in the cartel agreements, and the number of dyads in which both countries are covered by a news agency. As expected, the coverage increases over time, and more specifically rises sharply after each extension of the cartel agreements. We notice a big jump after the 1876 agreement, easily explained by the fact that at this date many countries were added to the cartel (South America and large parts of Asia). More descriptive statistics on news agency coverage are available in the appendix, figure 14 .

Telegraph data: Data on international telegraph links comes from two sources. For the submarine telegraph cables, we rely on the Journal Télégraphique, a monthly publication by the International Telegraph Union (ITU). In some issues, an appendix is available with an exhaustive list of the submarine cables in use and the date at which they started operating ${ }^{12}$. This data was collected by Roland Wenzlhuemer, who kindly accepted to share it with us. The last nomenclature dates back to 1903, before the end of our sample, but at this time the main submarine cables had already been laid down, and most of the countries were already telegraphically connected. Regarding the terrestrial telegraphic lines, no such nomenclature is available, so we had to rely on the visual analysis of maps from the "Bureau international des administrations télégraphiques", digitized and made available by the Bibliothèque nationale de France $(\mathrm{BnF})$. The list of the maps we used is available in the appendix, along with one example of such maps (figure 9). The first map dates back to 1856 and the last one to 1912 . Finally in order to start our sample in 1850, we use the list of the first international telegraphic lines from Wolff (1991).

\footnotetext{
12“Nomenclature des câbles formant le réseau sous-marin du globe dressée d'après des documents officiels par le Bureau international des administrations télégraphiques" in 1875, 1877, 1883, 1887, 1889, 1892, 1894, 1897, 1901 and 1903. See appendix for more details.
} 
Figure 3: Evolution over time of the news agency coverage

(a) Number of countries

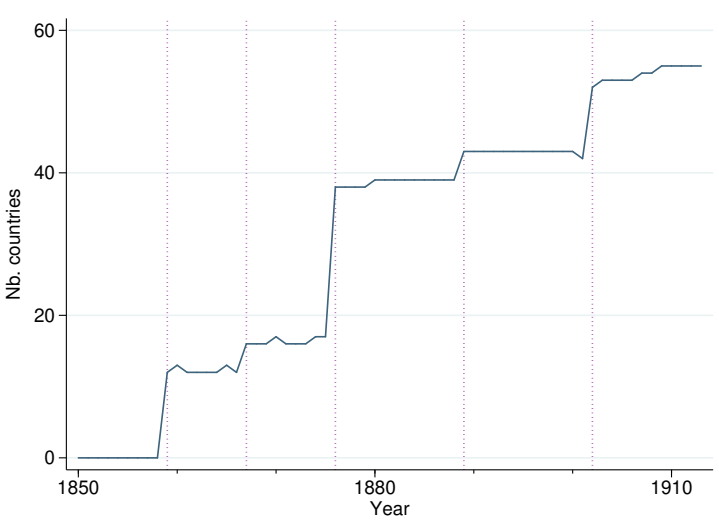

(b) Number of dyads

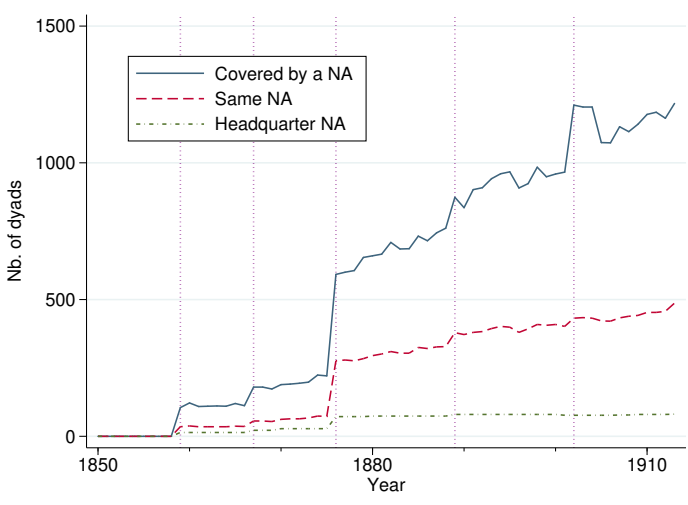

Notes: Each vertical purple dotted line corresponds to an agreement extending the geographic coverage of the cartel. In fig (b), the blue line counts the number of dyads that are covered by a news agency participating to the international news exchange agreements; the red dashed line counts the dyads that are covered by the same news agency and the yellow dotted line corresponds to the dyads in which the importer and the exporter are covered by the same news agency and one of them is the headquarter of the news agency.

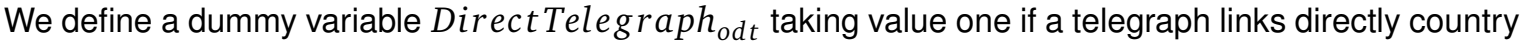
$o$ and country $d$ at date $t$. For the submarine cables, we know for sure the first year in which the two countries are linked since the construction dates are given in the nomenclatures. For the terrestrial cables, we assume that DirectTelegraph ${ }_{\text {odt }}=0$ until the first time we see the telegraph on a map. To clarify, the first telegraph between Chile and Argentina was built in $1871 .{ }^{13}$ We first see it on the 1875 map, so we code DirectTelegraph ${ }_{A R G, C H L, t}=0$ until $t=1874$. Nevertheless, given the relatively small time span between each map, the imprecision should be small. Since telegraphs can always be used in both directions, the link is symmetric, so DirectTelegraph $h_{\text {dt }}=$ DirectTelegraph $_{d o t}$. Based on the direct connections data, we build a dummy variable indicating whether any pair of countries is indirectly connected, meaning that the two countries are connected either directly or via one or many intermediary countries, i.e. they belong to the same connected sub-graph. For instance, if DirectTelegraph ${ }_{o k}=1$ and DirectTelegraph $h_{k d}=1$, then $T e l_{o d}=1$ even if DirectTelegraph ${ }_{o d}=0$. In more formal terms, two countries $o$ and $d$ are considered as indirectly connected if there exists at least one path of any length $n$ that connects $o$ to $d$.

Figure 4 depicts the number of countries with at least one international telegraph connection (left-hand side) and the number of dyads connected by the telegraph (right-hand side). We distinguish between the dyads connected by a submarine cable, the dyads directly connected (by land or submarine cables) and the dyads that are directly or indirectly connected. In all cases, the number of connections increases, but the number of direct connections lags far behind the total number of connections. This is due to the network

\footnotetext{
${ }^{13}$ Between Valparaiso (Chile) and Villa Nueva (Province of Córdoba, Argentina).
} 
Figure 4: Evolution over time of the telegraph coverage

(a) Number of countries

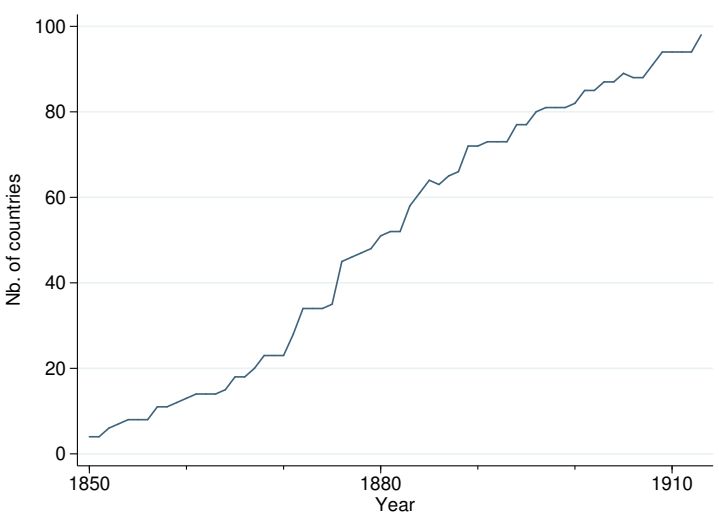

(b) Number of dyads

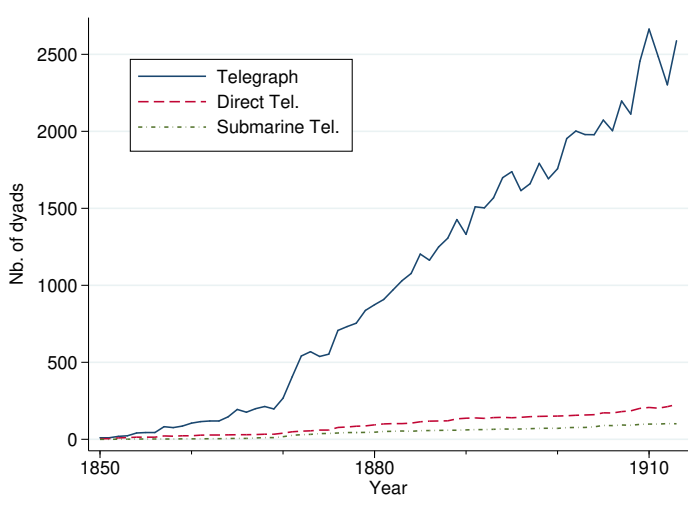

Notes: In fig (b), the blue line counts the number of dyads that are connected by a telegraph, directly or indirectly; the red dashed line counts the dyads that are directly connected and the green dotted line corresponds to the dyads that are connected by a submarine telegraph cable.

structure: adding a new direct link is likely to create more than one indirect link. Appendix figure 13 provides more descriptive statistics on the evolution over time of the number of telegraph connections.

This measure of telegraphic connection within a dyad has some drawbacks. First, it does not give any idea of the quality, and speed of the telegraphic connection between countries. It does not tell us about the speed at which information can be exchanged, we can calculate the shortest path but this not necessarily the fastest one as cables are not all of the same quality. Second, this measure tells us whether or not two countries are connected, but it does not tell us how much information is (and can be) exchanged between them. Nevertheless, we believe it is a valid proxy of the ability of two countries to communicate in a fast and reliable manner through this new technology. It differs considerably from the measure used in the first attempt to assess the effect of telegraph on trade (Lew and Cater 2006), namely the product of the number of telegraphs sent by each country. This variable is not bilateral in essence, two countries may indeed send a lot of telegraph but are not connected and therefore cannot communicate with each other. Moreover it does not allow the inclusion of destination-year and origin-year fixed effects, that are now standard in gravity equations.

\section{Main results}

\subsection{Estimation}

To determine the effect of news agencies and telegraph on bilateral trade, we estimate the panel version of gravity equations. As recalled by Head and Mayer (2014), a gravity equation for bilateral trade flows can be obtained from all the main models of international trade, so that our results do not require any assumption 
on the most appropriate way to model trade flows in the XIXth century. The gravity equation of trade flows refers to a multiplicative structure of the type:

$$
Y_{o d t}=O_{o t} D_{d t} \phi_{o d t} \eta_{o d t}
$$

where $Y_{o d t}$ denotes the bilateral trade flow between the origin $o$ and the destination $d$ during year $t . O_{o t}$ is a measure of the capability of country $o$ to export, whatever the destination, and $D_{d t}$ captures the general propensity of country $d$ to import, whatever the origin of these imports. $\phi_{\text {odt }}$ is a bilateral resistance term incorporating the effect of all the trade frictions between the importer and the exporter. Finally, $\eta_{\text {odt }}$ is an error term with mean zero. Among the factors determining the bilateral resistance term, $\phi_{\text {odt }}$, some are fixed over time, others do vary over time :

$$
\phi_{\text {odt }}=\underbrace{B_{o d}}_{\text {Fixed bilateral frictions }} \times \underbrace{\exp \left(\boldsymbol{\beta}^{\prime} \mathbf{X}_{o d t}\right)}_{\text {Time-varying bilateral frictions }}
$$

Plugging this into the gravity equation, and taking the expected value of trade flows:

$$
\begin{aligned}
& \mathbb{E}\left(Y_{\text {odt }}\right)=O_{o t} D_{d t} \phi_{o d t} \\
& \mathbb{E}\left(Y_{\text {odt }}\right)=\exp \left(\ln \left(O_{o t} D_{d t} \phi_{o d t}\right)\right) \\
& \mathbb{E}\left(Y_{\text {odt }}\right)=\exp (\underbrace{\ln \left(O_{o t}\right)}_{\mathrm{FE}_{o t}}+\underbrace{\ln \left(D_{d t}\right)}_{\mathrm{FE}_{d t}}+\underbrace{\ln \left(B_{o d}\right)}_{\mathrm{FE}_{o d}}+\boldsymbol{\beta}^{\prime} \mathbf{X}_{o d t})
\end{aligned}
$$

This leaves us with the following conditional expectation for the bilateral trade flow:

$$
\mathbb{E}\left(Y_{o d t}\right)=\exp \left(\mathrm{FE}_{o t}+\mathrm{FE}_{d t}+\mathrm{FE}_{o d}+\boldsymbol{\beta}^{\prime} \mathbf{X}_{o d t}\right)
$$

Equation (1) shows that if we include sets of importer $\times$ year, destination $\times$ year and country pair fixed effects, and if the vector of time varying frictions $\mathbf{X}_{o d t}$ is complete, then each component of the vector $\boldsymbol{\beta}$ can be recovered without bias. The variables we are interested in are part of $\mathbf{X}_{o d t}$, since they are bilateral and time varying, so that obtaining unbiased estimates of $\boldsymbol{\beta}$ is what we desire. Estimating equation (1), any country specific variable, such as the quality of institutions, GDP, or productivity is fully captured by the origin-time or destination-time fixed effects. Similarly, the specific nature of a relationship between two trade partners, i.e. the fact that two countries may trade more together because of cultural or historical factors, or for any other idiosyncratic reason, is captured by the dyadic fixed effects as long as it is not time varying.

As explained in the previous section, we constructed two dummy variables proxying for the bilateral coverage by a global news agency (NewsAgency ${ }_{\text {odt }}$ ) and the connection by a telegraph (Telegraph $\left.h_{\text {odt }}\right)$. Because the bilateral information flow should be higher when these two dummy variables both take value 1 , we are especially interested in their interaction term, NewsAgenc $y_{\text {odt }} \times$ Telegraph $_{\text {odt }}$. If news agencies and telegraphs are complementary, because the telegraph allows for a more efficient communication among the network of global news agencies, while news agencies provide content that can be shared with a wider 
audience than private telegrams, the effect of NewsAgenc $y_{\text {odt }} \times$ Telegraph $h_{\text {odt }}$ is expected to be positive: the importer and the exporter get more information on each other, which is expected to increase trade between them. NewsAgenc $y_{\text {odt }} \times$ Teleg raph $h_{\text {odt }}$ is not captured by the fixed effects since its value changes over time within a dyad and over trade partners within a country-year. The sign of the coefficients on

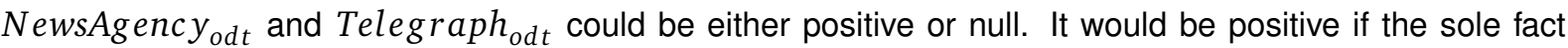
of being covered by a news agency (or benefiting from a telegraphic connection) increases the amount of information transmitted, or null if only the conjunction of the two matters.

News agency coverage and telegraphic links could be correlated with changes in the colonial ties linking both countries ${ }^{14}$, which are in turn linked to trade flows, so that failing to account for those ties may result in an omitted variable bias. Therefore, in our baseline specification, the vector of time-varying variables, $\mathbf{X}_{o d t}$,

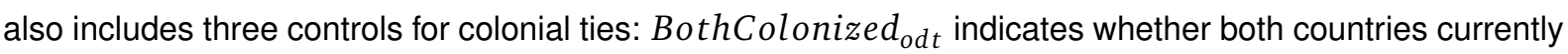

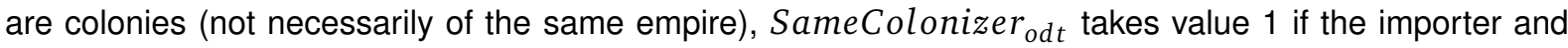
the exporter belong to the same colonial empire, i.e. are currently colonized by the same country, and finally MetropoleColony $y_{\text {odt }}$ captures the specific metropole-colony ties (the importer is the colonizer of the exporter, or vice-versa).

To summarize, the panel data gravity estimation allows us to get rid of potential confounding factors at the dyadic level and at the country-year level. The estimates are identified from time variations in trade flows, and therefore rely solely on dyads whose status changed over time. Concerning news agencies, the overwhelming majority of these changes consists in entering the cartel agreements. Very few countries are reassigned to another news agency, and no country is dropped out of the cartel agreements. For telegraphic connection, the changes comes from telegraphic links creations.

To estimate equation (1), two methods can be used. The first one consists in log-linearizing. Then, the trade friction coefficients $\beta$ can be estimated through OLS:

$$
\operatorname{Ln}\left(Y_{o d t}\right)=\mathrm{FE}_{o t}+\mathrm{FE}_{d t}+\mathrm{FE}_{o t}+\boldsymbol{\beta}^{\prime} \mathbf{X}_{o d t}+\varepsilon_{o d t}
$$

Nevertheless, this OLS estimator is biased under heteroskedasticity (Santos Silva and Tenreyro 2006). To overcome this, one can use a pseudo maximum-likelihood estimator, assuming either a Poisson distribution for the density function (Poisson Pseudo Maximum Likelihood, henceforth PPML), or a Multinomial distribution (Multinomial Pseudo Maximum Likelihood). Both assumptions yield identical estimates as long as destination fixed effects are included (Sotelo 2017), which is the case in all of our specifications. Besides the fact that it corrects for the heteroskedasticity driven bias affecting the OLS estimator, the PPML estimator essentially differs from its OLS counterpart on two accounts:

1. The weight put on large trade flows: PPML gives more importance to large trade flows than OLS (Head and Mayer 2014). To ensure that countries are treated more equally, Sotelo (2017) proposes to use market shares, i.e. trade flow between the two countries divided by total imports of the destination country.

\footnotetext{
${ }^{14}$ The colonial ties are not absorbed by the dyadic fixed effects since they vary over time during our period of interest.
} 
2. The ability to handle zero trade flows : because it relies on a log-linearization, OLS requires to drop the zeros, while PPML does not, allowing for the incorporation of an extensive margin in the estimates (by extensive margin, we mean the switch from zero trade to strictly positive trade for a given dyad). Whether this is a desirable feature or not depends on the (unknown) true nature of the zero trade flows: are they true zero trade flows or unrecorded trade flows?

Because of its ability to correct for the heteroskedasticity driven bias, PPML is our preferred estimator. Nevertheless, we provide additional results based on OLS estimations, that are not qualitatively different from the ones we obtain from the PPML estimations. When estimating PPML models, we use as dependent variable trade shares instead of trade levels, to ensure that the weighting scheme is more comparable to the one from the the OLS estimations. These trade shares are denoted $S_{\text {odt }}$ in the rest of the paper, and are defined as the share of imports of country $d$ coming from country $o$ :

$$
S_{o d t}=\frac{Y_{o d t}}{\sum_{o \neq d} Y_{o d t}}
$$

In our dataset, some zero trade flows are recorded, which correspond to cases in which the creators of TRADHIST considered that there was indeed a null trade flow between the two countries, i.e. that the missing trade flows was not due to a lack of data. However, this is necessarily based on assumptions on a threshold above which the data is deemed sufficiently complete to confidently attribute the absence of a recorded flow to an absence of transaction. Moreover, we merge some geographical entities to ensure the consistency of each country included in our dataset over the whole period of study, and zero trade flows are not defined for these newly created country pairs. Our approach is therefore to use the information on zero trade flows in our preferred specification, but to provide as robustness checks estimates from specifications in which we either drop all the zero trade flows, or assume that all the non strictly positive trade flows between any existing pair of countries actually are zero trade flows, i.e. forcing the sample to be perfectly balanced.

\subsection{Results}

Table 1 presents our main results. We estimate the panel gravity model from equation (1) using alternatively an OLS estimator, in columns (1) and (2), and a PPML estimator, in the other columns, (3) to (6). We also present results with or without controlling for colonial ties, and with different approaches in dealing with non strictly positive trade flows.

Column (4) is in our view the most appropriate specification: it corrects for the potential heteroskedasticity driven bias of the OLS estimates, while incorporating information from the most reasonable zero trade flows (the ones included in TRADHIST) and giving an equal weight to all countries thanks to the use of trade shares as dependent variable. With this specification, we find that the telegraph on its own increased trade by $38 \%$, news agencies by $33 \%$ (although this estimate is not significant, a point we comment below) while the combination of the two resulted in a magnified increase, $30 \%$ additional trade. The variable identifying 
Table 1: Effect of news agencies and telegraphs on trade flows, panel gravity estimates $(1850-1913)$

\begin{tabular}{|c|c|c|c|c|c|c|}
\hline & \multicolumn{2}{|c|}{ OLS } & \multicolumn{4}{|c|}{ PPML } \\
\hline & $\begin{array}{c}\operatorname{Ln}\left(Y_{\text {odt }}\right) \\
(1)\end{array}$ & $\begin{array}{c}\operatorname{Ln}\left(Y_{o d t}\right) \\
(2)\end{array}$ & $\begin{array}{l}S_{o d t} \\
(3)\end{array}$ & $\begin{array}{l}S_{o d t} \\
(4)\end{array}$ & $\begin{array}{c}S_{\text {odt }}>0 \\
(5)\end{array}$ & $\begin{array}{c}S_{o d t} \\
(6)\end{array}$ \\
\hline \multirow[t]{2}{*}{ News Ag. $\times$ Tel. } & $0.426^{b}$ & $0.427^{b}$ & $0.262^{c}$ & $0.259^{c}$ & $0.255^{b}$ & 0.319 \\
\hline & {$[0.188]$} & {$[0.188]$} & [0.158] & {$[0.156]$} & {$[0.111]$} & {$[0.204]$} \\
\hline \multirow[t]{2}{*}{ Telegraph } & $0.319^{b}$ & $0.323^{b}$ & $0.323^{a}$ & $0.334^{a}$ & $0.181^{c}$ & $0.383^{a}$ \\
\hline & {$[0.147]$} & {$[0.147]$} & {$[0.116]$} & {$[0.115]$} & {$[0.096]$} & {$[0.146]$} \\
\hline \multirow[t]{2}{*}{ News Agency } & 0.286 & 0.287 & 0.232 & 0.222 & 0.178 & 0.075 \\
\hline & [0.210] & {$[0.210]$} & [0.184] & {$[0.183]$} & {$[0.137]$} & {$[0.237]$} \\
\hline Observations & 59910 & 59910 & 83373 & 83373 & 59910 & 140506 \\
\hline Sample & Complete & Complete & Complete & Complete & Complete & Balanced \\
\hline Colony controls & & $\checkmark$ & & $\checkmark$ & $\checkmark$ & $\checkmark$ \\
\hline
\end{tabular}

\begin{abstract}
Note: Data is aggregated at the country pair $\times$ year level. The dependent variable is the log of the bilateral trade flow in columns (1) and (2) and the share of imports of country $d$ coming from country $o$ $\left(S_{\text {odt }}\right)$ in the remaining columns, (3) to (6). All estimations include destination $\times$ year, origin $\times$ year and country-pair fixed effects. NewsAg. $\times$ Tel. is a dummy indicating that both countries are covered by a news agency and linked by a telegraph. "Balanced" sample refers to the case in which we form all the possible combinations dyads $\times$ year and assign a zero trade flow if nothing was recorded in TRADHIST. In brackets are the standard errors, clustered by country-pair. Significance levels: ${ }^{a}: p<0.01 ;{ }^{b}$ : $p<0.05 ;^{c}: p<0.1$.
\end{abstract}

the improvement in information sharing between the two countries is the interaction term, and the fact that its effect is positive and significant confirms that improving the access to public information fosters trade.

In columns (1) and (3), we present results obtained when omitting the variables controlling for colonial ties. These controls include three dummy variables: one indicating that both countries are colonized (potentially by a different country), the other one that they are colonized by the same country (they belong to the same colonial empire) and the last one that a country is a colony and the other one is its colonizer. When comparing these estimations to their counterpart with colonial ties controls (columns (2) and (4) respectively), we see that the estimates are remarkably close, suggesting that the correlation between our variables of interests and the colonial status is low.

The results are qualitatively unchanged when we use an OLS estimator. The presence of both a news agency and a telegraph in both countries still has a positive and significant effect on trade, which is even a bit larger than the one found with a PPML estimation (a 53\% increase), but is also slightly less precisely estimated. For the telegraph, the effect as is remarkably close to the PPML estimate (38\% more trade). 
In columns (5) and (6), we experiment different assumptions on the appropriate way to treat zero trade flows. Column (5) presents our estimates after dropping all the zero trade flows. While the magnitude of the interaction term is left almost unchanged, the effect of the telegraph is reduced, suggesting that communication technologies per se have an important effect on the extensive margin of trade, i.e. on the probability that a dyad has a positive trade flow. In the last column (6), we conduct a different experiment, assuming that all the potential dyads for which we have no information in TRADHIST actually have a zero trade flow. With this balanced sample, the point estimates of the telegraph effect and of the interaction term grow, but the interaction term is less precisely estimated, and its effect is therefore not significant anymore.

The contribution of this paper is to establish the positive effect of a shock on information, identified by the joint presence of a news agency and a telegraphic link between the two countries. On top of being positive and significant, this pure effect of information is relatively large (a $30 \%$ increase in trade in our preferred specification). Interestingly, this magnitude is in line with the results of Dickstein and Morales (2018), who find that, for contemporary trade on chemicals, switching from minimal information to perfect foresight would result in aggregate exports rising by 25.1 to $33.5 \%$. With a value of -5 for the trade elasticity of trade flows with respect to trade costs, ${ }^{15}$ this $30 \%$ increase in trade value corresponds to a 5 percentage points decrease in the iceberg trade cost. ${ }^{16}$

The positive effect of telegraphs on trade is not a novel finding of this paper, but it confirms in a larger sample and over a longer time-horizon the results of Steinwender (2018). Her estimates imply an increase by $87 \%{ }^{17}$ of cotton exports from New-York to Liverpool after the opening of the transatlantic telegraph, an effect that incorporates both the reduction in communication costs and the more efficient provision of information, and that should therefore be compared to the one we find when summing the effects of the telegraph and of the interaction term.

The effect of news agencies per se (i.e., in the absence of telegraph) on trade is always positive, but never statistically significant. This suggests that in the absence of a telegraph connection, the news agencies were not able to efficiently share information. "Important news travelled along telegraph lines. And wherever there were such lines, there was also the latest news." (Wenzlhuemer 2013, p.91). The corollary is that wherever there was no telegraph line, the news agencies were not able to operate in a fully satisfactory manner.

In appendix table 6, we introduce alternatively in the regression each of our variables of interest, i.e. we estimate one specification with news agencies as the sole explanatory variable of interest, one with

\footnotetext{
${ }^{15}$ This value of the trade elasticity parameter comes from Fouquin and Hugot (2016), who estimate the elasticity of trade flows with respect to trade costs during the period we study and find it to be around -5 , a value remarkably close to the median of the estimates obtained on more recent data (Head and Mayer 2014)

${ }^{16}$ The trade effects we estimate are the product of the semi-elasticity of trade costs with respect to our information shock and the elasticity of trade flows with respect to trade costs:

$$
\frac{\partial \ln \left(Y_{o d t}\right)}{\partial X_{o d t}}=\frac{\partial \ln \left(Y_{o d t}\right)}{\partial \ln \left(\tau_{\text {odt }}\right)} \times \frac{\partial \ln \left(\tau_{\text {odt }}\right)}{\partial X_{o d t}}
$$

where $\tau_{\text {odt }}$ denotes the iceberg trade cost. Plugging in our estimates: $0.26=-5 x$, hence $x=-0.052$. Hence the 5 percentage points decrease in iceberg trade costs.

${ }^{17}$ Table 8 p.676, column (9), the coefficient associated to the telegraph dummy with log exports as dependent variable is 0.63 .
} 
telegraph only, and one with the interacted term only. The effects of both the telegraph and the news agencies appear a bit larger when the interaction is not properly accounted for, highlighting the necessity to consider simultaneously these two determinants of trade.

\section{Robustness checks}

All our specifications include time-varying origin and destination fixed effects, which rule out the hypothesis that our effect is driven by the general tendency of trade flows to rise over the period we study. These fixed effects also ensure that our estimates are isolated from channels not directly related to a decrease in bilateral trade frictions, such as an increase in GDP of the countries benefiting from news agency and telegraph coverage, or more openness to trade in general. Indeed these two factors depend solely on the origin or destination, and are therefore fully absorbed by the set of fixed effects.

We also include dyadic fixed effects which control for time-unvarying specific bilateral relationships. These dyadic fixed effects control for observable factors like distance or language proximity, but also for factors that would be harder to measure in a satisfactory manner, such as diplomatic or cultural proximity between the two countries. Therefore, the positive effect we find cannot be attributed to a cross-sectional positive correlation between our variable of interest and any omitted variable that would positively affect trade. In order for our identification to be biased, an unaccounted factor has to vary over time within a pair of countries and be correlated with news agency coverage and telegraphic connections.

We identify two such threats to our identification. The first one is that the date at which a telegraph is built between a country pair or at which the country pair is included in the syndication agreement may be driven either by anticipation of large trade flows or respond to observed past large trade flows. The second one is that it may be driven by diplomatic factors that would correlate with the bilateral trade policy, i.e. two countries may have a more favorable relationship that would be associated both with telegraph \& news agencies link and lower trade barriers.

Our first robustness check is to isolate the sub-sample of the treated units for which the treatment date could be endogenous, in order to focus on the treated units for which it is exogenous. This is done in sub-section 4.1, where we present results estimated solely from indirect connections, and find that the positive trade effects we identified still do exist when relying on the most exogenous source of variation. To address more specifically the second threat, we check in sub-section 4.2 whether our variables of interest are correlated with tariffs on a subsample of our dataset (the dyads for which we do have tariff rates, that are unfortunately not available for our complete universe). We find no significant correlation, which suggests that trade policy is not closely tied with telegraphic and news agency linkages. Finally, in sub-section 4.3, we present the results of an event-study. They confirm the absence of pre-trend in trade for the dyads that will be connected in the future. 


\subsection{Separating direct and indirect connections}

The timing of construction of a telegraphic line may be linked to anticipated trade flows, or to past trade flows between the two countries that would become connected. Even though the technical difficulties of the construction process made the precise timing of a successful telegraph opening hard to predict, especially for submarine cables, as argued by Steinwender (2018), our approach is relying on long-run time variations, which means that this short-run randomness in opening date may not be sufficient to ensure exogeneity of our explanatory variable. Our coefficient on the trade effect of telegraph could be either upward or downward biased, depending on the source of endogeneity. If telegraphic lines are built between countries for which it is expected that the trade relationship will deepen in the future, then we would overestimate the trade benefits of the telegraph. Conversely, if telegraphic lines are built between countries that already have a deep trade relationship and therefore a demand that is already very high for telegraphic services, then there would be less room for future trade growth and we would underestimate the trade effect of the telegraph.

To alleviate these concerns, we focus on indirect connections. While countries may broadly control the date at which a direct telegraphic link is established between them, they have less power in deciding when the last missing segment to create a telegraphic path between them will be built. For instance, Brazil and China became indirectly linked in 1874, after the completion of a transatlantic telegraph between Portugal and Brazil (with relays in Madeiras and Cabo Verde). Arguably trade between China and Brazil had little influence on the timing of this connection. Therefore, we estimate separately the effect of direct and indirect connections, by adding a dummy variable DirectTelegraph ${ }_{\text {odt }}$ that indicates a direct telegraph link. The coefficient on Telegraph odt then captures exclusively the effect of indirect links, and should provide a more accurate estimate of the causal effect.

Endogeneity concerns on the date of inclusion in the news agencies' syndication agreement are addressed with a similar strategy. The decision to add a country is linked to the expected profits from selling news in this country, which in tun may be linked to trade flows. Note however that the link has to be truly bilateral: the fact that countries are added based on their total economic size is not an issue for our identification since we include time varyin origin and destination fixed effects in our estimations. Also, we underline again that additions to the news agencies' syndication agreement occurred by waves: groups of countries were added in five staggered extensions, so the precise date of inclusion is unlikely to be at the hands of the concerned countries. If there was nevertheless a link between the date at which a pair of countries is included in the syndication agreement and bilateral trade flows, it could lead either to over- or underestimation of the causal effect. If two countries are included because of the prospect of large trade flows (and high demand for bilateral information), then we would overestimate the information effect. Conversely, if two countries are included because they faced an idiosyncratic positive shock on their past trade flows, we would underestimate the information effect.

We make use of the fact that the news agencies were not national but global operators. It is unlikely that a country would be able to exert pressure on a large foreign company to curb its choices towards covering certain areas. Lobbying efforts are easier when the firm is domestic. For instance, it would be harder for 
Spain than for France to influence the choices of Havas, the French news agency. Our strategy is therefore to decompose the country pairs between those in which one of the countries is the headquarter of the news agency, and the ones in which none of the countries is. The date of treatment is more likely to be endogenous in the former group, in which the news agency is a domestic firm for one of the countries than in the latter one, in which the news agency is a foreign operator for both countries. For instance, Argentina and Australia started being included in the news agency network in 1876, arguably an exogenous timing since the country pair became linked without any particular intent as a by-product of the agreement's extension. To isolate the dyads in which we could fear endogeneity, we add a dummy HeadquarterNewsAgenc $y_{\text {odt }}$, taking value 1 when both countries are covered by the same news agency and one of the countries is the headquarter of the news agency. Havas is considered to be based in France, Reuters in the UK, and Wolff in Germany.

Figure 5: Effect of telegraphs and news agencies on bilateral trade flows, distinguishing between direct and indirect links.

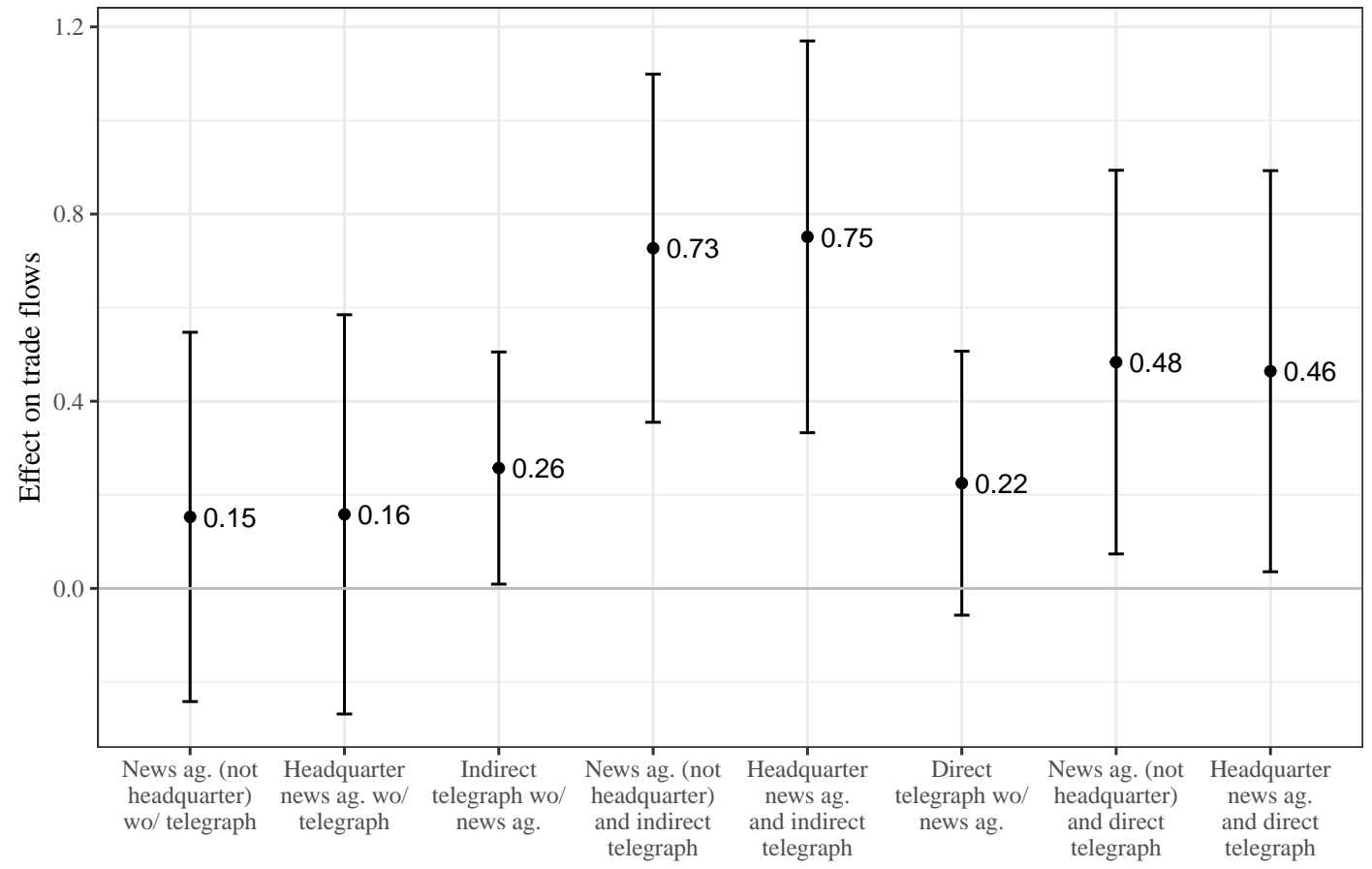

Notes: PPML estimates of the effect on trade flows, where the reference situation is the absence of news agency and telegraph. Interpretation: when two countries become indirectly linked by a telegraph but are not covered by a news agency, trade is expected to increase by $30 \%\left(e^{0.26}-1\right)$. Bars indicates the $95 \%$ confidence interval, with standard errors clustered at the country-pair level.

Figure 5 presents the results of this estimation. We use our preferred specification: PPML estimator, with trade shares as dependent variables, on the complete sample (including the zero trade flows provided in TRADHIST). However, in this graph the reference situation is the absence of both a news agency and a telegraph, i.e. the interacted terms do not correspond to additional effects as in table 1, but rather to total 
effects on trade. Additional effects are harder to interpret and are therefore presented later, in table 2.

We find that, in the absence of a telegraph, the trade effect of news agencies is not very different whether or not one of the countries is the headquarter of the news agency (a $17 \%$ vs a $16 \%$ increase in trade flows). This confirms that the endogenous timing of news agency coverage is not a big concern. Coefficients are a bit less similar when we compare direct and indirect telegraphic links: a $25 \%$ increase in trade for direct telegraphic lines vs a $30 \%$ increase for indirect telegraphic connections. This is consistent with the scenario in which direct telegraphic lines are built across countries that already had high trade levels before the construction, and for which there is less room for trade growth.

Most importantly, the trade effect of being indirectly connected both by a telegraphic line and a news agency largely exceeds the sum of the two effects taken separately $\left(108 \%\left(e^{0.73}\right)\right.$ vs $51 \%\left(e^{0.15+0.26}\right)$ ), which confirms that, even when focusing on the dyads for which the connection date is more exogenous, we do find a positive and significant contribution of our information shock. However, the additional trade effect of being covered by a news agency is significantly lower for the country pairs that were directly connected by a telegraph than for those that were indirectly connected, suggesting that these country pairs already had abundant information on each other, and therefore benefited less from the arrival of a news agency. For these country pairs whose coverage date is more endogenous, there seems to be no magnified effect in presence of both a news agency and a telegraphic line.

In table 2, we present results for a variety of specifications. The setup is slightly different from the one used in figure 5 , since effects can now directly be interpreted as additional marginal effects, while they were total marginal effects in the graph. For instance, the coefficient on the interaction term "News Agency $x$ Telegraph" denotes the additional effect of being both indirectly covered by a news agency and indirectly connected by a telegraph. This formulation allows to test directly our hypothesis of interest, i.e. whether the positive shock on information corresponding to this scenario increases trade.

In column (1), we remind the results of our preferred baseline specification, corresponding to column (4) of table 1. Column (2) corresponds to exactly the same specification as the one plotted in figure 5 . The interaction term purged from direct connections remains positive and significant, with a magnitude close to our baseline estimate (trade increases by an additional 37\% in presence of both a news agency and a telegraph). This also confirms what we were able to visualize from the graph: no difference in trade effect when one of the countries is the headquarter of the news agencies, a slightly lower (but not significantly lower) effect when the telegraph link is direct, and a significantly lower additional trade effects of news agencies when the telegraphic link is direct, suggesting that these country pairs started from high trade levels and therefore benefited less from the increase in information available.

Column (3) confirms that the colonial ties controls do not play a large role in our estimation, since the estimates are barely affected by their omission. In column (4), we use an OLS estimator and find that the results are essentially unchanged, except on two accounts: the additional effect of news agencies appear larger, and direct telegraphic links now appear to have a positive and significant effect on trade. ${ }^{18}$ In column

\footnotetext{
${ }^{18}$ This suggests that direct telegraph lines did not induce dyads with zero trade flows to trade, but rather intensified trade between dyads that already used to trade (in other words, direct telegraphic lines mostly affected the intensive margin). This hypothesis is
} 
Table 2: Panel gravity estimates, separating direct and indirect connection

\begin{tabular}{|c|c|c|c|c|c|}
\hline & $\begin{array}{c}(1) \\
S_{o d t} \\
\end{array}$ & $\begin{array}{c}(2) \\
S_{o d t} \\
\end{array}$ & $\begin{array}{c}(3) \\
S_{o d t} \\
\end{array}$ & $\begin{array}{c}(4) \\
\operatorname{Ln}\left(Y_{o d t}\right) \\
\end{array}$ & $\begin{array}{c}(5) \\
S_{o d t}>0\end{array}$ \\
\hline News Ag. $\times$ Tel. & $\begin{array}{l}0.259^{c} \\
{[0.156]}\end{array}$ & $\begin{array}{c}0.317^{b} \\
{[0.158]}\end{array}$ & $\begin{array}{c}0.316^{b} \\
{[0.161]}\end{array}$ & $\begin{array}{c}0.564^{a} \\
{[0.193]}\end{array}$ & $\begin{array}{c}0.310^{a} \\
{[0.116]}\end{array}$ \\
\hline News Ag. $\times$ Direct Tel. & & $\begin{array}{c}-0.211^{c} \\
{[0.111]}\end{array}$ & $\begin{array}{c}-0.196^{c} \\
{[0.114]}\end{array}$ & $\begin{array}{c}-0.607^{a} \\
{[0.148]}\end{array}$ & $\begin{array}{c}-0.302^{a} \\
{[0.091]}\end{array}$ \\
\hline Headquarter News Ag. $\times$ Tel. & & $\begin{array}{l}0.019 \\
{[0.123]}\end{array}$ & $\begin{array}{l}0.017 \\
{[0.123]}\end{array}$ & $\begin{array}{l}-0.186 \\
{[0.161]}\end{array}$ & $\begin{array}{l}0.126 \\
{[0.114]}\end{array}$ \\
\hline Headquarter News Ag. $\times$ Direct Tel. & & $\begin{array}{l}-0.044 \\
{[0.159]}\end{array}$ & $\begin{array}{l}-0.046 \\
{[0.160]}\end{array}$ & $\begin{array}{l}0.300 \\
{[0.193]}\end{array}$ & $\begin{array}{l}0.204 \\
{[0.137]}\end{array}$ \\
\hline Telegraph & $\begin{array}{c}0.334^{a} \\
{[0.115]}\end{array}$ & $\begin{array}{c}0.257^{b} \\
{[0.117]}\end{array}$ & $\begin{array}{c}0.251^{b} \\
{[0.118]}\end{array}$ & $\begin{array}{l}0.219 \\
{[0.147]}\end{array}$ & $\begin{array}{l}0.118 \\
{[0.099]}\end{array}$ \\
\hline Direct Tel. & & $\begin{array}{l}-0.032 \\
{[0.104]}\end{array}$ & $\begin{array}{l}-0.035 \\
{[0.106]}\end{array}$ & $\begin{array}{c}0.463^{a} \\
{[0.161]}\end{array}$ & $\begin{array}{c}0.176^{b} \\
{[0.087]}\end{array}$ \\
\hline News Agency & $\begin{array}{l}0.222 \\
{[0.183]}\end{array}$ & $\begin{array}{l}0.153 \\
{[0.187]}\end{array}$ & $\begin{array}{l}0.168 \\
{[0.188]}\end{array}$ & $\begin{array}{l}0.291 \\
{[0.213]}\end{array}$ & $\begin{array}{l}0.203 \\
{[0.141]}\end{array}$ \\
\hline Headquarter News Ag. & & $\begin{array}{l}0.005 \\
{[0.122]}\end{array}$ & $\begin{array}{l}0.002 \\
{[0.123]}\end{array}$ & $\begin{array}{l}-0.101 \\
{[0.169]}\end{array}$ & $\begin{array}{c}-0.218^{b} \\
{[0.111]}\end{array}$ \\
\hline $\begin{array}{l}\text { Observations } \\
\text { Estimator } \\
\text { Sample } \\
\text { Colony controls }\end{array}$ & $\begin{array}{c}83373 \\
\text { PPML } \\
\text { Complete } \\
\end{array}$ & $\begin{array}{c}83373 \\
\text { PPML } \\
\text { Complete } \\
\square\end{array}$ & $\begin{array}{c}83373 \\
\text { PPML } \\
\text { Complete }\end{array}$ & $\begin{array}{c}59910 \\
\text { OLS } \\
\text { Complete } \\
\checkmark\end{array}$ & $\begin{array}{c}59910 \\
\text { PPML } \\
\text { Complete } \\
\square\end{array}$ \\
\hline
\end{tabular}

Note: Data is aggregated at the country-pair $\times$ year level. The dependent variable is the share of imports of destination $d$ coming from origin $o$ in the remaining columns. All specifications include destination $\times$ year, origin $\times$ year and country-pair fixed effects. DirectTel. indicates a direct telegraph connection between $o$ and $d$, while HeadquarterNewsAg. indicates that both countries are covered by the same news agency and one of the two is the headquarter of the news agency. In brackets are the standard errors, clustered by country-pair. Significance levels: ${ }^{a}: p<0.01 ;{ }^{b}: p<0.05 ;^{c}: p<0.1$.

(5), we switch back to PPML but restrict the sample to strictly positive trade flows: the additional trade effect of news agencies and telegraphs is now very close to our baseline estimate from column (2), suggesting that the high magnitude observed in column (4) had more to do with the use of an OLS estimator than with the omission of the extensive margin.

The results in table 2 are consistent with the picture obtained by running a series of cross-sectional

comforted by the fact that, when we switch back to PPML but restrict the sample to strictly positive trade flows the coefficient on direct telegraphic lines again appears positive and significant (see column (5)). 
gravity estimations, one for each year of the sample. We define a dummy variable identifying the countries that are covered by a news agency for the first time in the 1876 cartel agreement, and check year after year whether, in cross-section, these countries trade more together. Similarly, we estimate the cross-sectional trade effect for the headquarter dyads that entered the cartel agreement in 1876. The evolution over time of these cross sectional estimates is plotted in figure $6 .{ }^{19}$

On the right hand side graph, we see that the headquarter dyads tend to trade more together than what would be predicted by a standard gravity equation, even before the news agency coverage actually starts for them, i.e. before 1876. This suggests the existence of a privileged relationship that is not improved by the additional information, and even seems to fade away in the long-run. The pattern is very different for the "indirect" news agency connections (left hand side of the graph): the coefficients are never significant before the start of the news agency coverage, suggesting that there is no special relationship between these pairs of countries before 1876. After this date however, their trade relationship starts improving and a decade later they trade significantly more than the benchmark from the gravity equation.

Figure 6: Cross-sectional gravity estimates, 1876 cartel agreement

(a) Covered by a news agency in the 1876 cartel agreement

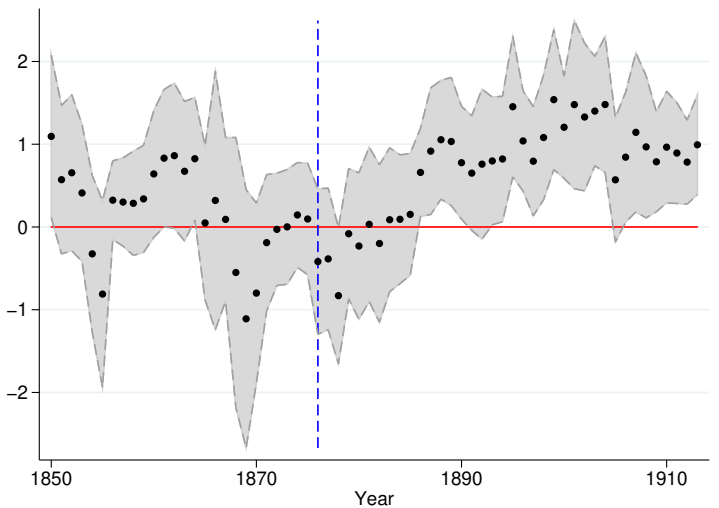

(b) Headquarter News Agency

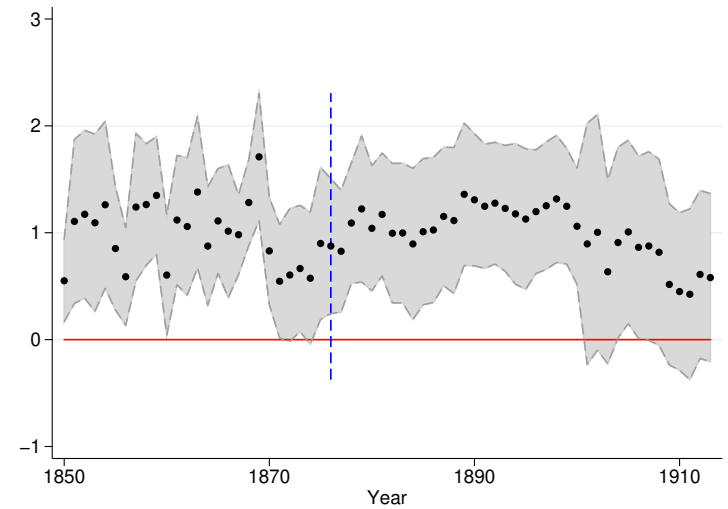

Notes: Each dot corresponds to a PPML estimate from a cross-sectional gravity equation, with trade shares as dependent variable. Left hand side: dummy indicating that the dyad is covered first in the 1876 cartel agreement. Right hand side: dummy indicating that one of the country is the headquarter of the news agency, and that year of inclusion in the cartel agreements is 1876. Each regression includes origin and destination fixed effects, and controls for the log of distance.

\footnotetext{
${ }^{19}$ For the curious reader, similar plots are available for the other variables included in our regressions, namely the colony control variables and the geographic distance (figure 17 in the appendix). Of particular interest is the fact that the so-called "distance puzzle" (i.e. the idea that the distance coefficient remains remarkably stable despite deep changes in the trade environment) is as vivid during the XIXth century as during the XXth century.
} 


\subsection{Proxy trade policy with tariffs}

Another approach to circumvent the issue of potential endogeneity of coverage by telegraph and news agencies is to have a look at the most easily quantifiable measure of trade policy: tariffs. TRADHIST provides information on the average customs duties for 8000 dyads-year. This measure is far from exhaustive, and has some well-known limitations. ${ }^{20}$ Nevertheless it is likely to remain a good proxy for the bilateral openness between two countries. ${ }^{21}$

Ideally, we would include tariffs in the baseline regression as a robustness check. This is however not feasible given that we have tariffs only for a small subsamble of the dyads. The estimation would therefore be performed on a very different sample than in the baseline specification. However, if tariffs were correlated with our variables of interest in a way that may affect our estimates, then we would expect a within-dyad link between tariffs and news agency / telegraph coverage on the sample for which we have tariff data. To test this, we regress bilateral tariffs on our variables of interest and a set of dyadic and year fixed effects (table 3). We find no significant correlation between tariffs and our news agency / telegraph coverage dummies, which suggests that trade policy is not a major threat to identification.

\subsection{Event study}

The construction of the telegraph network and the extension of the global news agencies cartel were progressive over time, so that the first year in which the country is "treated" (i.e when both a telegraph link and a news agency coverage is available) differs across pairs of countries. There is a wide dispersion in treatment dates (plotted in figure 11, in the appendix). The fact that not all units in the panel receive treatment at the same time, and that some units are never treated allows estimating a dynamic model (event-study) to describe the evolution over time of the outcome before and after the treatment, yielding insights on the duration and the evolution of the treatment effect.

This is done by constructing a set of dummy variables, each corresponding to a certain number of years separating the dyad from its treatment date. Let $K_{o d t}$ denote the number of years to treatment for dyad od at time $t$, so that, for instance, $K_{F R A, B R A, 1870}=-6$, since the first year in which both France and Brazil are covered by a news agency and a telegraph is 1876 . Therefore, for this observation, the dummy $\mathbb{1}\left\{K_{\text {odt }}=-6\right\}$ turns on, while all the other "years to treatment" dummy variables take value zero $\left(\mathbb{1}\left\{K_{o d t}=k\right\}=0 \forall k \neq-6\right)$. Our aim is to estimate the marginal effects of each of these dummy variables, that we denote $\gamma_{k}$. If a dyad is never treated, as is the case for $77.84 \%$ of our sample, all the "years to treatment" dummy variables take value zero, i.e. $\mathbb{1}\left\{K_{o d t}=k\right\}=0 \forall k$

We regress the log of bilateral trade flows on dyadic and year fixed effects, the controls for colonial ties, the telegraph dummy and the news agency dummy, and on the above-described set of dummy variables

\footnotetext{
${ }^{20}$ If tariffs are very high on a given product, imports should decrease, therefore the weighted average of tariff is likely to be biased downwards.

${ }^{21}$ We are especially reassured by the way this tariff measure correlates with our main variables of interest in a series of crosssectional regressions (table 8 , in the appendix). This confirms our priors, without threatening our identification strategy, which relies on time-variations.
} 
Table 3: Correlation between bilateral tariff rates and our variables of interest.

\begin{tabular}{lcccc}
\hline & \multicolumn{4}{c}{ Average Tariff ${ }_{\text {odt }}$} \\
\cline { 2 - 5 } & $(1)$ & $(2)$ & $(3)$ & $(4)$ \\
\hline News Ag. $\times$ Tel. & & & & \\
& -0.665 & 0.123 & -1.567 & -0.089 \\
News Ag. $\times$ Direct Tel. & {$[3.183]$} & {$[3.130]$} & {$[3.769]$} & {$[3.618]$} \\
& & -4.042 & & 0.931 \\
Headquarter News Ag. $\times$ Tel. & & {$[3.192]$} & & {$[5.665]$} \\
& & & 4.528 & 5.672 \\
Headquarter News Ag. $\times$ Direct Tel. & & & {$[5.223]$} & {$[5.232]$} \\
& & & & $-13.455^{b}$ \\
Telegraph & & & & {$[6.333]$} \\
& -3.474 & -4.341 & -4.570 & $-6.517^{b}$ \\
Direct Tel. & {$[2.662]$} & {$[2.650]$} & {$[2.777]$} & {$[2.766]$} \\
& & 1.746 & & 0.654 \\
News Agency & & {$[2.291]$} & & {$[4.038]$} \\
Headquarter News Ag. & 4.677 & 4.560 & -0.171 & -1.305 \\
& {$[4.120]$} & {$[4.062]$} & {$[4.409]$} & {$[4.357]$} \\
Observations & & & 7.164 & 8.838 \\
Dyad FE & & & {$[5.758]$} & {$[5.889]$} \\
Year FE & & & & \\
\hline
\end{tabular}

Note: Data is aggregated at the country pair $\times$ year level. The dependent variable is the average tariff rate. All specifications include country-pair and year fixed effects. In brackets are the standard errors, clustered by country-pair. Significance levels: ${ }^{a}: p<0.01 ;^{b}: p<0.05 ;^{c}: p<0.1$.

indicating the number of years to treatment:

$$
\ln \left(Y_{o d t}\right)=\sum_{k=-40+}^{40+} \gamma_{k} \mathbb{1}\left\{K_{o d t}=k\right\}+\mathrm{FE}_{o d}+\mathrm{FE}_{t}+\boldsymbol{\beta}^{\prime} \mathbf{X}_{o d t}+\varepsilon_{o d t}
$$

where $k=40+$ means "40 years or more after the treatment".

Figure 7 shows how the treatment effect evolves before and after the treatment date. Before the treatment (left hand-side of the graph, with "years to treatment $<0$ "), we see that there is no particular trend, i.e. that pre-treatment trade never significantly differs from its treatment date level. In other words, dyads 
Figure 7: Evolution of bilateral trade before and after news agency and telegraph coverage (event-study)

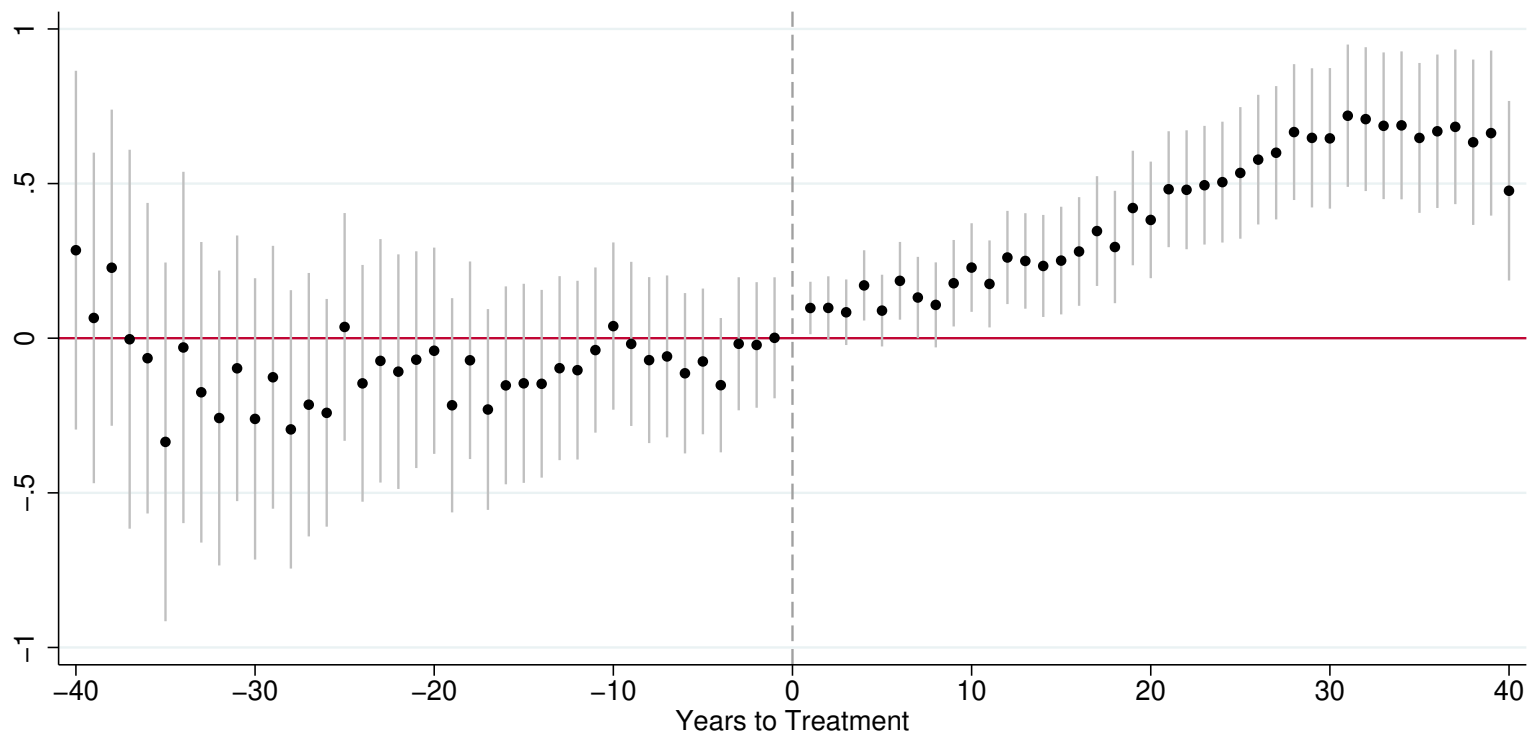

Note: Each point on the graph corresponds to the coefficient on a dummy variable taking value 1 if the number of years to treatment is $k$ ( $k$ negative before treatment and positive after). The treatment date is the first year in which both countries of the dyad are covered by a news agency and connected by the telegraph. The complete specification is provided in eq. (2)

that are going to be connected by a news agency and a telegraph do not seem to be on an increasing or decreasing time trend before actually being connected. The picture is very different after the treatment (right hand-side of the graph): the dyads immediately start trading more, the increase is steady up to 30 years after the treatment, at which point the trade effect stabilizes at a rather high level.

The magnitude of the effect is comparable to the one found in our baseline estimations. The fact that it is long lasting is consistent with the permanent nature of the treatment: once a dyad is connected by a telegraph and a news agency, it never switches back to non coverage, so the additional flow of information never stops. The slow increase suggests that, on top of direct knowledge of the foreign market conditions, our information shock affected trade through long-run channels, potentially an increase in Foreign Direct Investments, international migrations, or even a convergence in cultural tastes.

\section{Testing the information channel}

The previous section identifies a positive and significant impact of the telegraph and news agency coverage on trade. We attribute this effect to an improved access to information. However, our variables of interest are only proxies for the increase in the quantity and quality of information. To rule out other channels 
through which they may have affected trade, we test for the presence of effects that that are more specific to the information channel.

In the first sub-section, we document an increase in the volatility of trade flows after coverage by a news agency and a telegraph, consistent with a better ability of traders to adapt to varying market conditions. In a second sub-section, we provide quantitative evidence of an increase in the coverage of foreign countries in the press when they become connected by a telegraph and a news agency. This shows that the delivered information is indeed more abundant between the countries after they benefit from the positive shock we rely on.

\subsection{Trade volatility}

In this sub-section, we test a prediction of the Steinwender (2018) model linking trade and information: a reduction in information frictions increases trade variance. Indeed, exports and imports react to changes in expected demand from other countries. In the extreme case without any information, exporters ship every year the same amount, corresponding to the expected demand. With more information, exporters can respond faster and better to demand fluctuations. With perfect information the variance of exports should be equal to the variance of demand as the exporting country can perfectly adapt to the local demand.

We assess whether trade flows between two countries become more volatile after these two countries are covered by a news agency. To this end, we use several measures of volatility. The first one (column (1) in table 4 is the usual sample standard deviation. We compute for each dyad the standard deviation of trade flows before and after the dyad is covered by a news agency. We then regress this sample standard deviation on a dyadic fixed effect and a dummy taking value 1 if both countries are covered by a news agency:

$$
\left(\widehat{\operatorname{Var}_{p}}\left(Y_{o d}\right)\right)^{1 / 2}=\mathrm{FE}_{o d}+\beta_{1} T e l_{o d p}+\beta_{2} N A_{o d p}+\beta_{3} N A_{\text {odp }} \times T e l_{\text {odp }}+\varepsilon_{\text {odp }}
$$

The second measure is the absolute value of the deviation of the trade flow at time $t$ to the mean trade flow in each period (before and after news agency coverage): $\left|Y_{o d t}-\bar{Y}_{o d p(t)}\right|$. The advantage of this measure is that it allows having several observations within each dyad for the two time periods (before and after being covered by a news agency). Its drawback is that it can be very noisy, especially with historical datasets that may contain more errors than recent ones. We regress this absolute deviation on destinationyear, origin-year and dyadic fixed effects, and a dummy taking value 1 if both countries are covered by a news agency:

$$
\left|Y_{o d t}-\bar{Y}_{o d p(t)}\right|=\mathrm{FE}_{o d}+\mathrm{FE}_{o t}+\mathrm{FE}_{d t}+\beta_{1} T e l_{o d t}+\beta_{2} N A_{o d t}+\beta_{3} N A_{o d t} \times T e l_{o d t}+\varepsilon_{o d t}
$$

The level of our volatility measure does not have any meaningful interpretation, we are mostly interested in its change over time. For all possible versions of the outcome variable, we observe a significant and positive impact of the news agency coverage on the volatility of trade flows. This result is consistent with the 
idea that more information is available thanks to the news agencies, which allows trade partners to adapt to the demand shocks.

Table 4: Effect of news agency and telegraphs on trade volatility.

\begin{tabular}{lcccccc}
\hline & $\begin{array}{c}(1) \\
\text { Standard } \\
\text { Deviation }\end{array}$ & $\begin{array}{c}(2) \\
\text { Absolute } \\
\text { Deviation }\end{array}$ & $\begin{array}{c}\text { Absolute } \\
\text { Deviation }\end{array}$ & $\begin{array}{c}(4) \\
\text { Absolute } \\
\text { Deviation }\end{array}$ & $\begin{array}{c}(5) \\
\text { Log of Absolute } \\
\text { Deviation }\end{array}$ & $\begin{array}{c}\text { Log of Absolute } \\
\text { Deviation }\end{array}$ \\
\hline \multirow{2}{*}{$\mathrm{NA}_{\text {odt }} \times \mathrm{Tel}_{o d t}$} & $742,259^{a}$ & $543,376^{a}$ & $600,525^{a}$ & $702,133^{a}$ & $0.672^{a}$ & $0.700^{a}$ \\
& {$[94,746]$} & {$[125,333]$} & {$[130,750]$} & {$[199,400]$} & {$[0.140]$} & {$[0.122]$} \\
Tel $_{\text {odt }}$ & & $183,238^{a}$ & $156,144^{a}$ & $306,314^{a}$ & $0.872^{a}$ & $0.726^{a}$ \\
& & {$[43,094]$} & {$[39,933]$} & {$[81,863]$} & {$[0.0881]$} & {$[0.0755]$} \\
$\mathrm{NA}_{o d t}$ & & $-130,861$ & $-264,732^{b}$ & $-381,128^{b}$ & 0.0273 & 0.0113 \\
& & {$[102,553]$} & {$[105,574]$} & {$[162,226]$} & {$[0.124]$} & {$[0.110]$} \\
Observations & 1194 & 117993 & 117993 & 62224 & 79715 & 62065 \\
Sample & Complete & Complete & Complete & Flow $>0$ & Complete & Flow>0 \\
\hline
\end{tabular}

Note : All specifications include dyadic fixed effects. All specifications year fixed effects, except columns (1) and (2). Standard errors are clustered at the dyad level. In columns (4) and (6), the zero trade flows are omitted. Significance levels: ${ }^{a}: p<0.01 ;^{b}: p<0.05 ;^{c}: p<0.1$

\subsection{Text analysis}

In this section, we provide evidence of an increase in the coverage of foreign countries in French newspapers when these countries benefit from a telegraph connection with France or are included in the news agencies' syndication agreement. This analysis relies on a corpus of articles from the 16 main French newspapers, processed during the Europeana Newspapers project. ${ }^{22}$

For each newspaper and country, we count on a yearly basis the number of days in which the country appears at least once in the newspaper's articles. We define an occurrence as the presence in the text of either the country name or the capital name. We then create five distinct groups of countries, based on their date of accession to the news agencies' syndication agreement (1859, 1867, 1876, 1889 or 1902), and estimate separately in each of these groups the effect of news agencies and telegraph on the number of days of presence:

$$
\begin{array}{r}
N \text { bDaysPresence }{ }_{n c t}=\exp \left(\mathrm{FE}_{n t}+\mathrm{FE}_{n c}+\sum_{\text {group }}\left[\beta_{1, \text { group }}\left(T e l_{c t} \times \mathbb{1}_{c \in \text { group }}\right)+\right.\right. \\
\left.\left.\beta_{2, \text { group }}\left(N A_{c t} \times T e l_{c t} \times \mathbb{1}_{c \in \text { group }}\right)\right]+\varepsilon_{n c t}\right)
\end{array}
$$

\footnotetext{
${ }^{22}$ More precisely, the dataset contains optical character recognition (OCR)'s transcription of the text of about 2 million pages, from L'Action française, Le Constitutionnel, La Croix, L'Echo de Paris, Le Figaro, Le Gaulois, L'Humanité, L'Intransigeant, Le Journal des débats politiques et littéraires, Le Matin, Le Petit Journal, Le Petit Parisien, La Presse, Le Siècle, Le Temps, L'Univers.
} 
where $c$ indexes the country, group the group of countries to which the country belongs, based on its accession date to the syndication agreement, $n$ the newspaper and $t$ the year. The specification includes newspaper $\times$ year fixed effects that account for the fact that the total article lengths may vary differently over time depending on the newspaper, and newspaper $\times$ country, which means that we rely on variations over time of the country coverage within the newspaper. To summarize, we estimate whether the space devoted to a country within each newspaper increases when this country's telegraph and news agency status switches from "not included" to "included", allowing for heterogeneous effects depending on the wave of news agencies coverage extension to which the country belongs. Note that by construction the coefficient on news agencies alone is not identifiable since within a group all countries have the same accession date, so that the time fixed effects fully capture the news agencies effect.

An important limitation to this exercise is that the sample is entirely made of French newspapers, which only allows us to estimate the effect by relying on on the different coverage dates with respect to France, instead of the more diverse set of bilateral coverage dates used to obtain the estimates on trade flows in the two previous sections. In other words, the sample is much more limited in terms of geographical scope, which limits the sources of variations we can use to identify the potential effect.

Our results are plotted in figure 8 . We find that the extensions that triggered the largest effect are the 1876 and 1889 agreements. This is probably due to the fact that these extensions included countries on which France likely had fewer information. On the contrary, earlier agreements covered either direct neighbors of France, or other European countries, for which it is likely that French newspapers already had more information. Moreover, we have a lower number of newspapers in our sample at the start of the period, leading to noisier estimates. This may explain why, even though they are always positive, the estimates are very low for the two first extensions, and not significant. Interestingly, the telegraph effect is always positive and significant in all but one group of countries. This implies that the telegraph was also a key determinant of the amount of public information available, but as argued in previous sections it also had a massive effect on private communication costs and can therefore not be used to isolate the pure effect of information on trade. 
Figure 8: Effect of telegraphs and news agencies on the country coverage in French newspapers, by year of entry into the news agencies's syndication agreement.

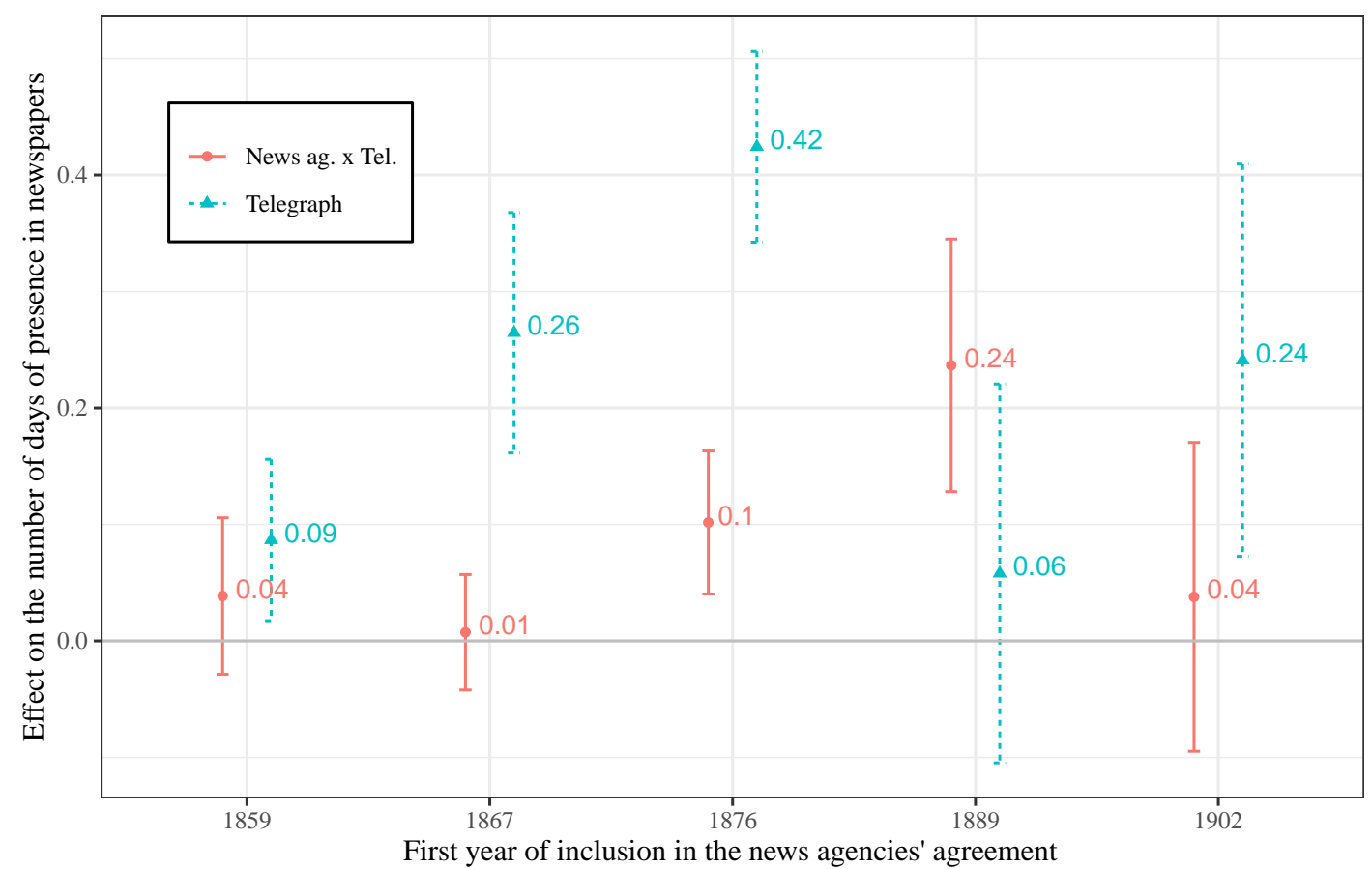

Notes: Notes: PPML estimates, with newspaper $\times$ year and newspaper $\times$ country fixed effects. Bars indicates the $95 \%$ confidence interval, with standard errors clustered at the country $\times$ year level. We distinguish groups of countries based on their date of accession to the news agencies' syndication agreement, and allow for heterogeneous effects between those groups.

\section{Conclusion}

We use the joint expansion of the telegraph and the news agencies to disentangle the pure information effect from the effect of reduced communication costs. The positive trade effect of linking two countries through the telegraphic network is magnified when these two countries are also both part of a news agency syndication agreement facilitating the exchange of information. We estimate that the decrease in coordination costs allowed by the telegraph raised the value of trade by $40 \%$, while the increase in the flow of information associated with the coverage by one of the global news agencies resulted in an additional $30 \%$ growth of trade.

The positive and significant effect of the telegraph and news agencies interaction subsists when focusing on indirect connections, which are less likely to suffer from the potential endogeneity bias linked to expectations of the operators. Additionally, we document patterns consistent with an increase in the flow of information: the variance of trade increases after the connection by a telegraph and a news agency, suggesting an improvement in the ability to adapt to demand shocks, and the presence of a foreign country in French newspapers increases after this country is linked to France by a telegraph and a news agency. 
While estimated from a historical event, the results are relevant to understand contemporary trade flows, since exporters still may lack the necessary information, despite considerable improvement in communication technologies.

This paper does not take a stance on the precise mechanism through which better access to information on foreign countries affects trade. On top of the improved knowledge of foreign market conditions, news agencies and telegraphs may have affected other outcomes such as Foreign Direct Investment, human migration flows or even cultural tastes. We leave for future research to delve into these potential channels. 


\section{References}

Albert, Pierre (2010). Histoire de la presse. Presses Universitaires de France.

Allen, Gene (2013). Making national news: A history of Canadian Press. University of Toronto Press.

Allen, Treb (2014). "Information Frictions in Trade". Econometrica 82.6, pp. 2041-2083.

Bakker, Gerben (2014). "How they made news pay: news traders' quest for crisis-resistant business models".

Bielsa, Esperança (2008). "The pivotal role of news agencies in the context of globalization: a historical approach”. Global Networks 8.3, pp. 347-366.

Dasgupta, Kunal and Jordi Mondria (2018). "Inattentive importers". Journal of International Economics 112, pp. $150-165$.

Dickstein, Michael J and Eduardo Morales (2018). "What do exporters know?” The Quarterly Journal of Economics 133.4, pp. 1753-1801.

Ejrnæs, Mette and Karl Gunnar Persson (2010). "The gains from improved market efficiency: trade before and after the transatlantic telegraph". European Review of Economic History 14.3, pp. 361-381.

Estevadeordal, Antoni, Brian Frantz, and Alan M Taylor (2003). "The rise and fall of world trade, 1870-1939". The Quarterly Journal of Economics 118.2, pp. 359-407.

Fouquin, Michel and Jules Hugot (May 2016). Two Centuries of Bilateral Trade and Gravity Data: 1827-2014. Working Papers 2016-14. CEPII.

Head, Keith and Thierry Mayer (2014). "Gravity Equations: Workhorse, Toolkit, and Cookbook". the Handbook of International Economics. Vol. 4. Elsevier. Chap. 3, pp. 131-195.

Jensen, Robert (2007). "The digital provide: Information (technology), market performance, and welfare in the South Indian fisheries sector". The Quarterly Journal of Economics 122.3, pp. 879-924.

Juhász, Réka and Claudia Steinwender (2018). "Spinning the web: Codifiability, information frictions and trade". NBER working paper.

Lenoir, Clemence, Julien Martin, and Isabelle Mejean (2020). "Search Frictions in International Good Markets".

Lew, Byron and Bruce Cater (2006). "The telegraph, coordination of tramp shipping, and growth in world trade, 1870-1910". European Review of Economic History 10.2, pp. 147-173.

Malgouyres, Clément et al. (2019). "Technology-induced Trade Shocks? Evidence from Broadband Expansion in France". mimeo.

Martin, Marc (1997). Médias et Journalistes de la République. Odile Jabob. 
Pascali, Luigi (2017). "The wind of change: Maritime technology, trade, and economic development". American Economic Review 107.9, pp. 2821-54.

Santos Silva, João and Silvana Tenreyro (2006). "The Log of Gravity". The Review of Economics and Statistics 88.4, pp. 641-658.

Sotelo, Sebastian (2017). "Practical Aspects of Implementing the Multinomial PML Estimator".

Steinwender, Claudia (Mar. 2018). "Real Effects of Information Frictions: When the States and the Kingdom Became United". American Economic Review 108.3, pp. 657-96.

Unesco (1952). News Agencies, Their Structure and Operation. Greenwood Press.

Wenzlhuemer, Roland (2013). Connecting the Nineteenth-Century World. Cambridge University Press.

Wolff, Jacques (1991). "Structure, fonctionnement et évolution du marché international des nouvelles. Les agences de presse de 1835 à 1934". Revue Economique 42.3, pp. 575-601. issn: 0035-2764. 


\section{Appendices}

\section{A Data}

\section{A.1 Construction of the database}

\section{A.1.1 News agency coverage:}

Table 5: Countries added by each cartel agreement (source: Wolff (1991))

\begin{tabular}{|c|c|c|c|c|c|}
\hline Agreement & Havas & Reuters & Wolff & $\mathrm{AP}$ & CorrBureau \\
\hline 1859 & $\begin{array}{c}\text { France } \\
\text { Spain } \\
\text { Italy } \\
\text { Ottoman Emp. }\end{array}$ & $\begin{array}{l}\text { Great Britain } \\
\text { Ireland }\end{array}$ & $\begin{array}{c}\text { Germany } \\
\text { Russia } \\
\text { Denmark } \\
\text { Netherlands } \\
\text { Sweden-Norway } \\
\text { Finland } \\
\text { Iceland }\end{array}$ & USA & \\
\hline 1867 & $\begin{array}{c}\text { Belgium } \\
\text { Ottoman Emp. } \\
\text { Egypt } \\
\text { Portugal }\end{array}$ & $\begin{array}{c}\text { Belgium } \\
\text { Ottoman Emp. } \\
\text { Egypt } \\
\text { Netherlands }\end{array}$ & & & Austria-Hungary \\
\hline 1876 & $\begin{array}{c}\text { South America } \\
\text { Switzerland } \\
\text { Indochina }\end{array}$ & $\begin{array}{c}\text { Far-East } \\
\text { Australia } \\
\text { New-Zealand } \\
\text { Switzerland }\end{array}$ & & & \\
\hline 1889 & $\begin{array}{c}\text { Greece } \\
\text { Bulgaria } \\
\text { Romania } \\
\text { Ottoman Emp. }\end{array}$ & Greece & & & $\begin{array}{c}\text { Serbia } \\
\text { Bulgaria } \\
\text { Romania } \\
\text { Ottoman Emp. }\end{array}$ \\
\hline 1902 & & & & $\begin{array}{c}\text { Central America } \\
\text { Puerto-Rico } \\
\text { Philippines } \\
\text { Cuba } \\
\text { Hawaii }\end{array}$ & \\
\hline
\end{tabular}

\section{A.1.2 Submarine telegraph cables:}

Data shared by Roland Wenzlhuemer, built from the "Nomenclature des cables formant le réseau sousmarin du globe dressée d'après des documents officiels par le Bureau international des administrations télégraphiques", published in:

1. Journal télégraphique 3, no 12 (1875)

2. Journal télégraphique 3, no 29 (1877) 
3. Journal télégraphique 7, no 5 (1883)

4. Journal télégraphique 11, no 4 (1887)

5. Journal télégraphique 13, no 9 (1889)

6. Journal télégraphique 16, no 4 (1892)

7. Journal télégraphique 18, no 10 (1894)

8. Journal télégraphique 21, no 11 (1897)

9. Journal télégraphique 25 (1901)

10. Journal télégraphique 27 (1903)

\section{A.1.3 Terrestrial telegraph cables:}

We constructed the database using a set of historical telegraph network maps whose references are provided below.

1. The Electric \& International Telegraph Company's Map of the Telegraph Lines of Europe Published under the Authority of the Electric Telegraph Company by Day \& Son, Lithographers to the Queen, 1856

2. Carte générale des grandes communications télégraphiques dans le Monde, dressée d'après des documents officiels par le Bureau international des administrations télégraphiques. C. v. Hoven, Imprimerie Lips (Berne), 1875

3. Carte générale des grandes communications télégraphiques dans le Monde, dressée d'après des documents officiels par le Bureau international des administrations télégraphiques. C. v. Hoven, (Berne), 1881

4. Carte des communications télégraphiques internationales et du régime extra-européen par le Bureau International des Administrations télégraphiques ; dressée et gravée par C.v. Hoven, (Berne), 1888

5. Carte des communications télégraphiques internationales et du régime extra-européen par le Bureau International des Administrations télégraphiques ; dressée et gravée par C.v. Hoven, (Berne), 1892

6. Carte des communications télégraphiques du régime européen dressée d'après des documents officiels par le Bureau international des administrations télégraphiques ; dessinée et gravée par C. v. Hover, (Berne), 1898

7. Carte générale des grandes communications télégraphiques dans le Monde, dressée d'après des documents officiels par le Bureau international des administrations télégraphiques. C. v. Hoven, (Berne), 1901 
Figure 9: Map of the telegraph lines in 1875

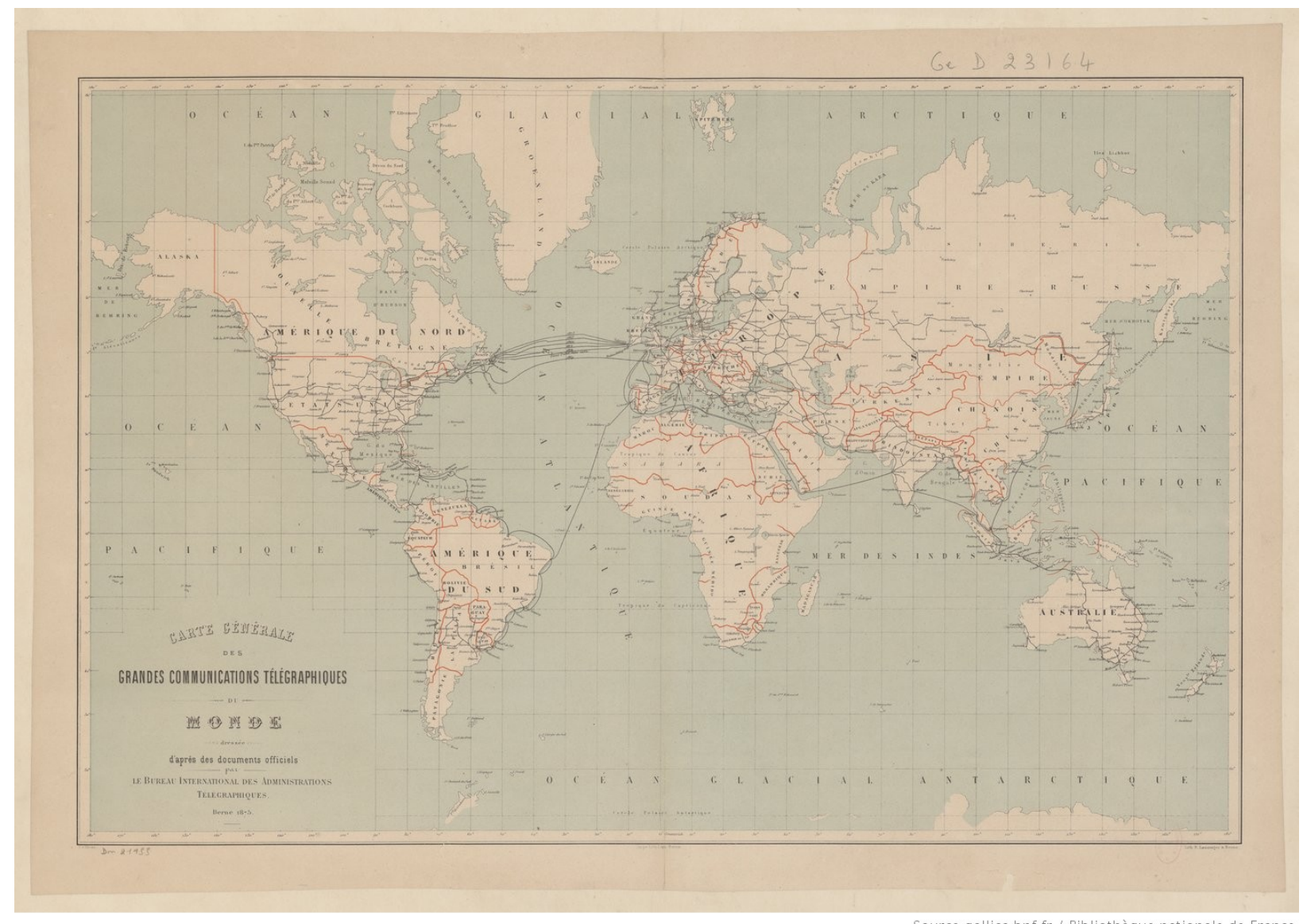

Source gallica.bnf.fr / Bibliothèque nationale de France

Source: gallica.bnf.fr / BnF

8. Carte générale des grandes communications télégraphiques dans le Monde, dressée d'après des documents officiels par le Bureau international des administrations télégraphiques. C. v. Hoven, (Berne), 1912 


\section{A.2 Descriptive Statistics}

Figure 10: Average tariff rate on French imports

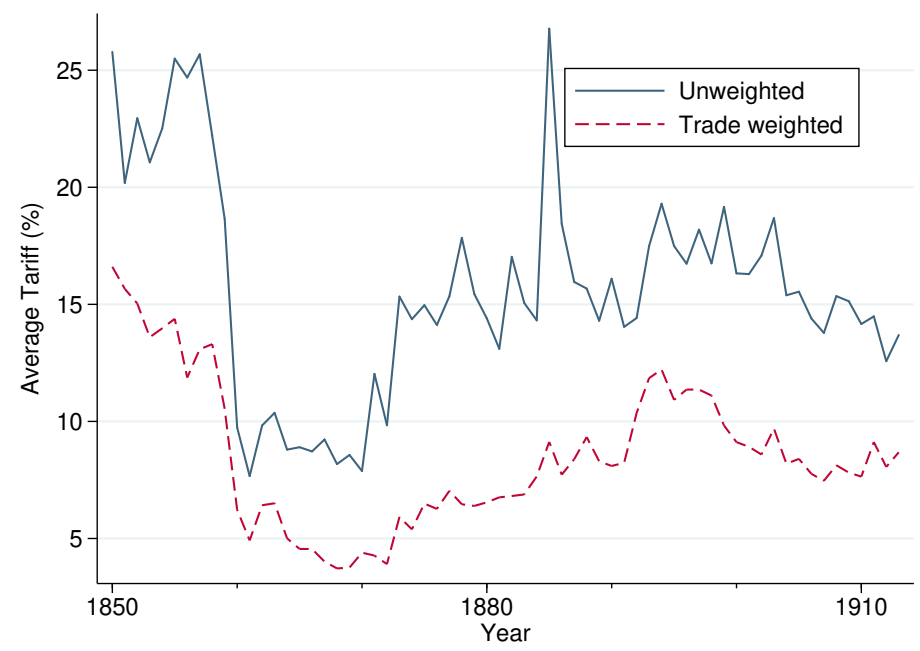

Notes: To compute the "unweighted" tariff, each origin is given the same weight, while for the "trade weighted" tariff, each origin is weighted by its trade flow with France.

Figure 11: Distribution of the "treatment dates" (event-study)

(a) Distribution of the first years in which dyads become connected by a telegraph and covered by a news agency

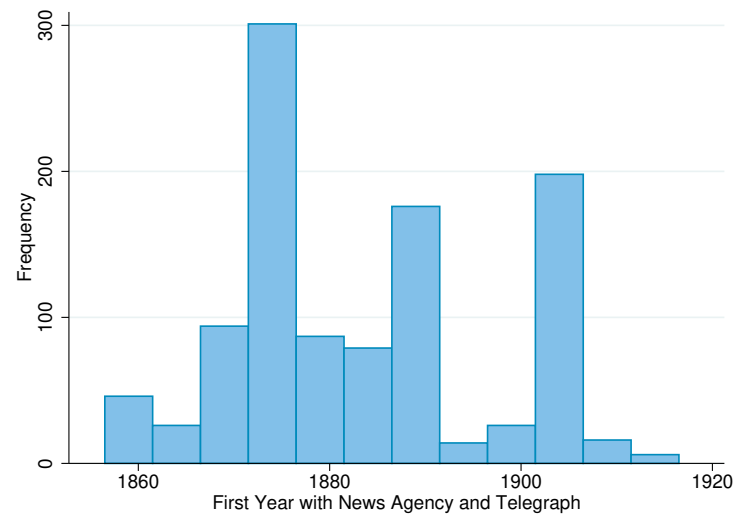

(b) Distribution of the difference between the first year of news agency coverage and the first year telegraph connection

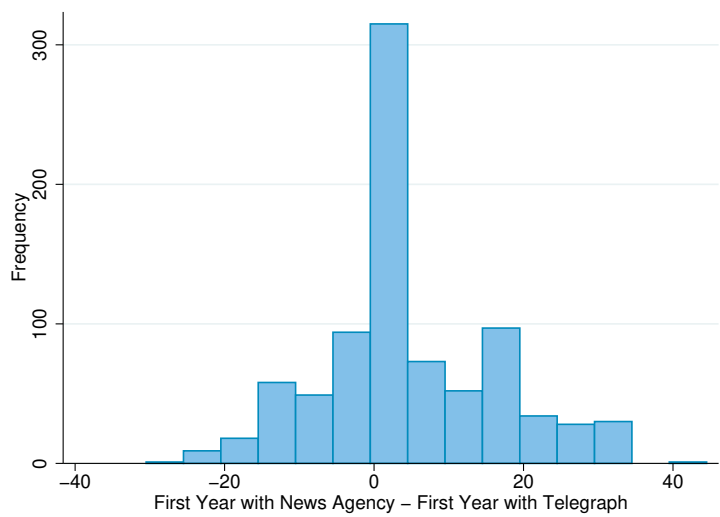

Notes: Among the dyads that end up being covered by a global news agencies and connected by a telegraph (the "treatment group"), we plot the distribution of the treatment year (a) and the distribution of the difference between the first year of news agency coverage and the first year telegraph connection (b). 
Figure 12: Evolution over time of the number of exporters and dyads, of the average trade flow per dyad and country, and of total trade

(a) Number of exporters

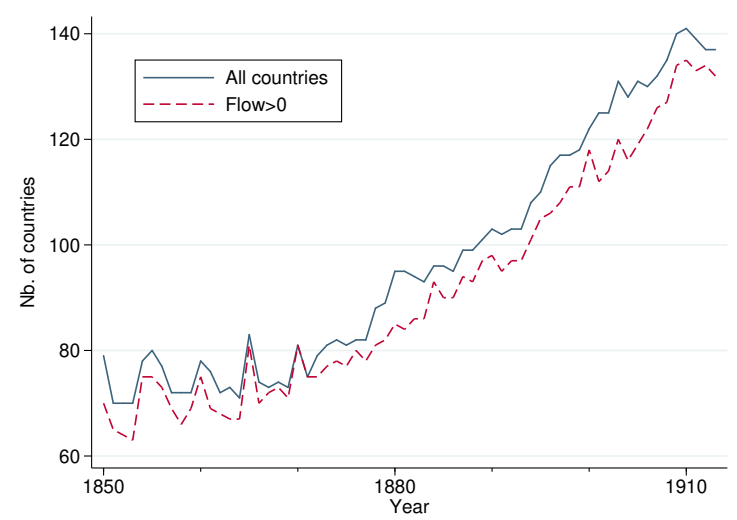

(c) Average trade flow per exporter (in millions GBP)

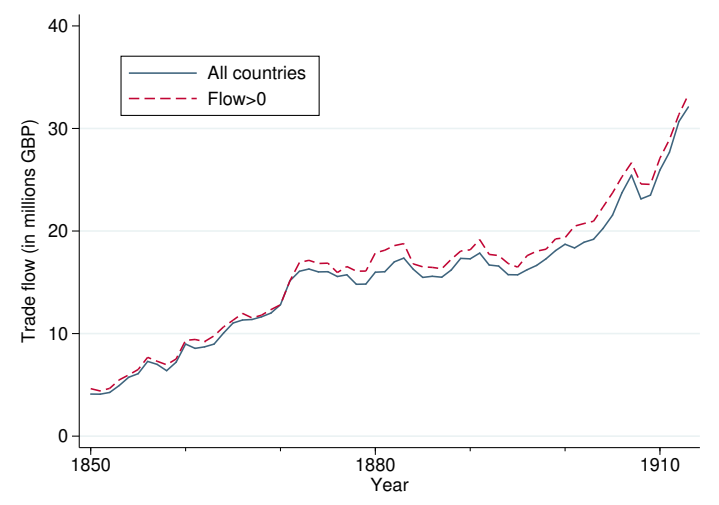

(b) Number of dyads

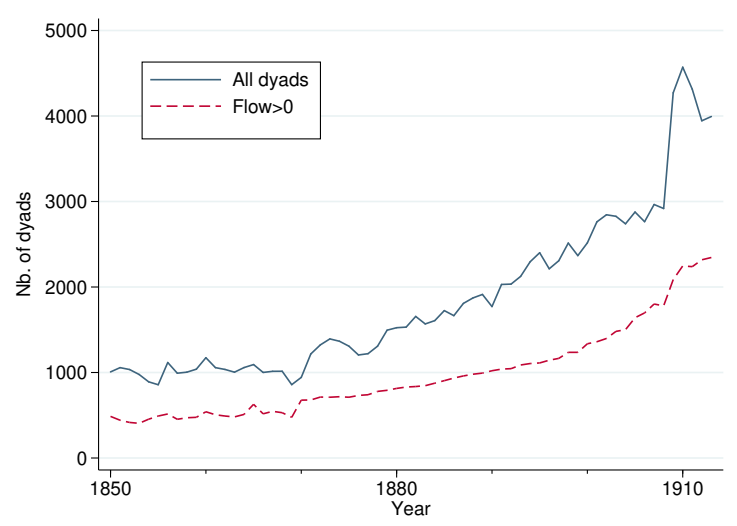

(d) Average trade flow per dyad (in millions GBP)

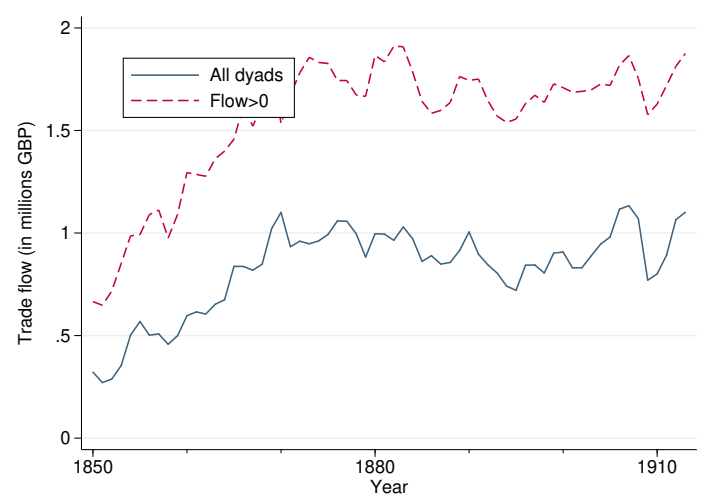

(e) Total trade (in billions GBP)

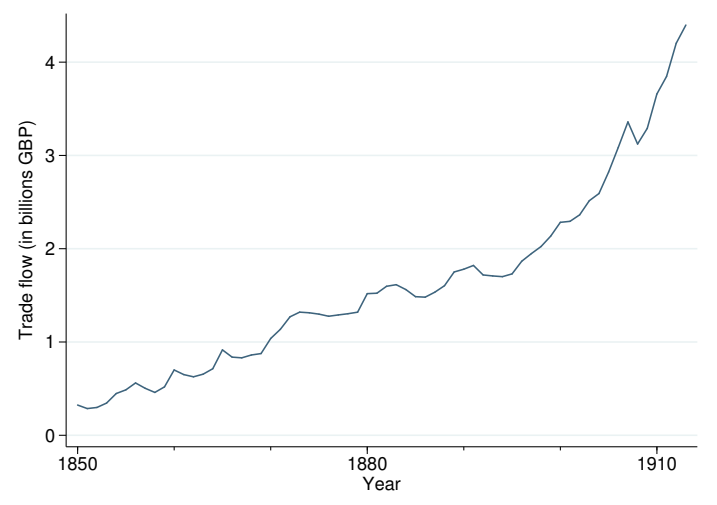


Figure 13: Evolution over time of the telegraph coverage

(a) Number of countries

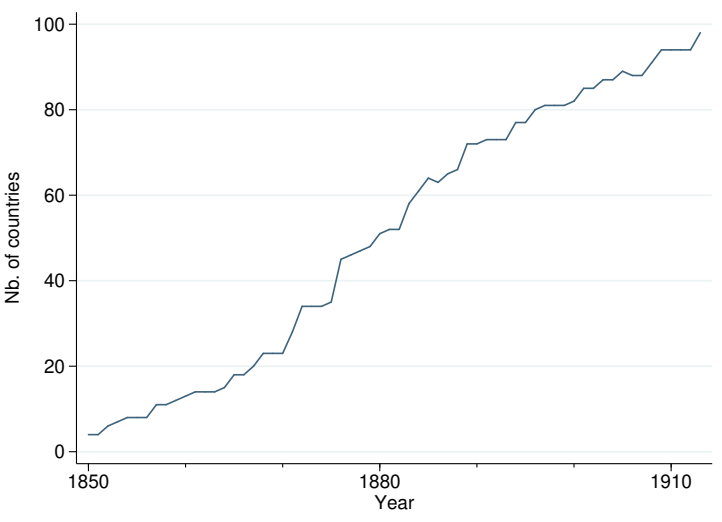

(c) Number of dyads

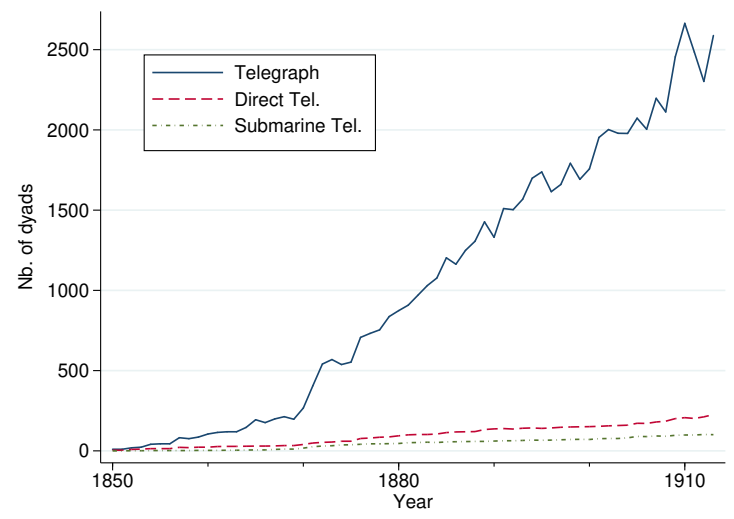

(e) Trade (in billions GBP)

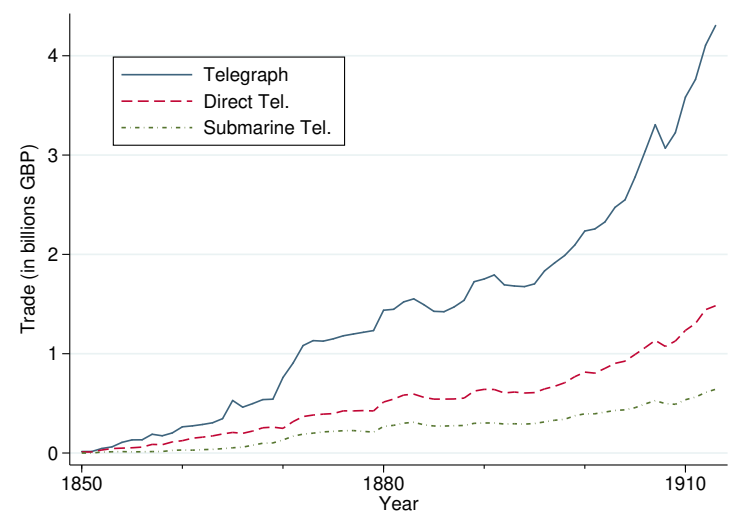

(b) Share of countries (in \%)

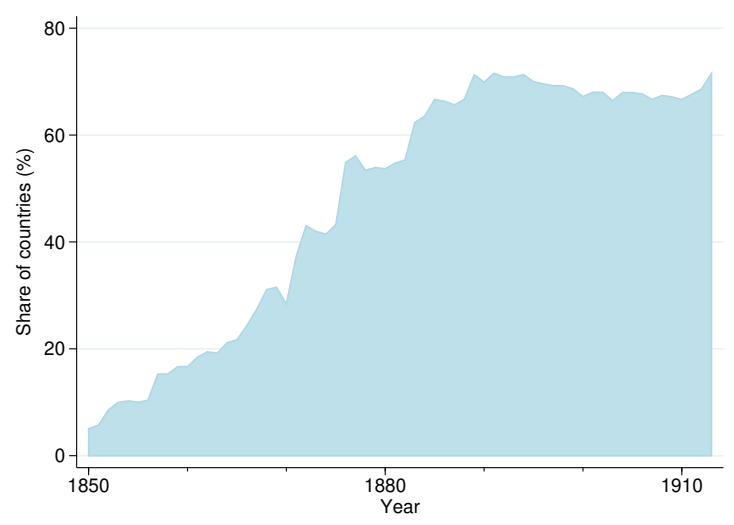

(d) Share of dyads (in \%)

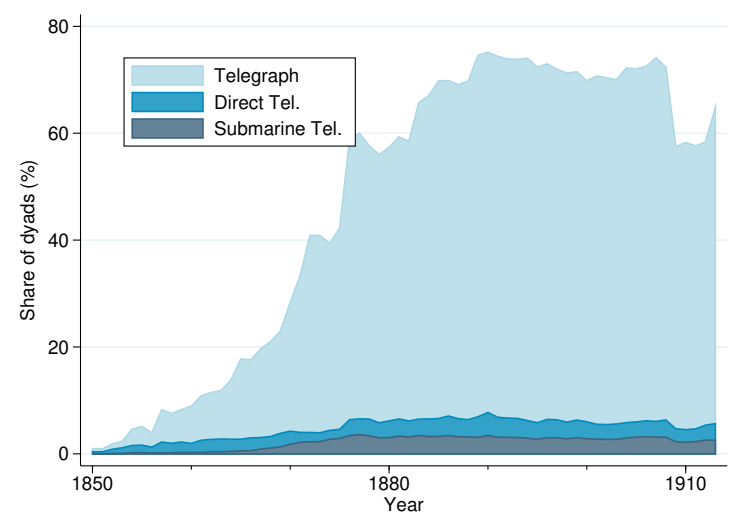

(f) Share of trade (in \%)

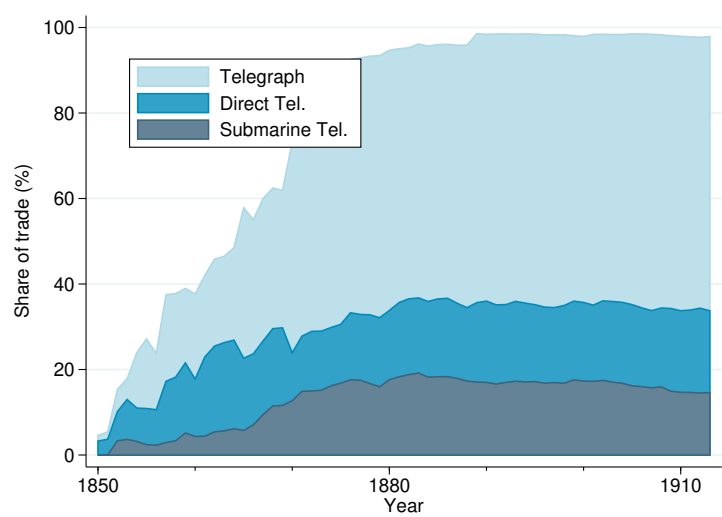


Figure 14: Evolution over time of news agency coverage

(a) Number of countries

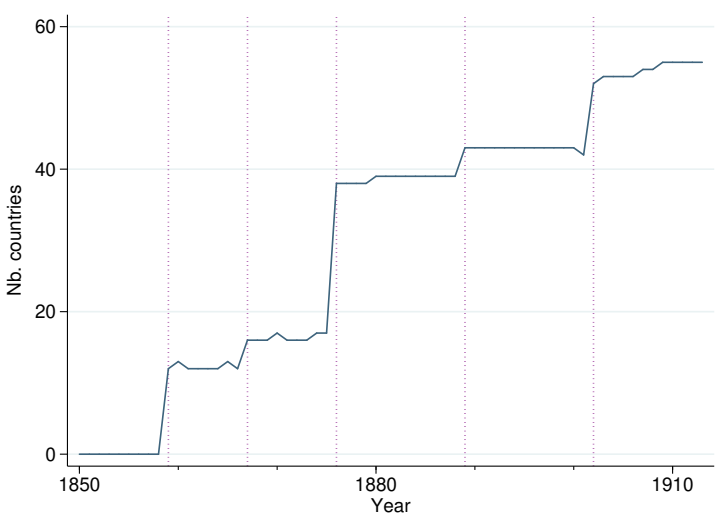

(c) Number of dyads

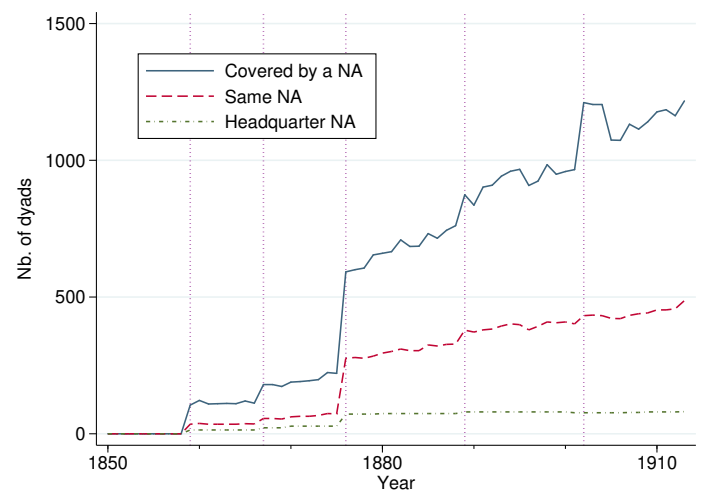

(e) Trade (in billions GBP)

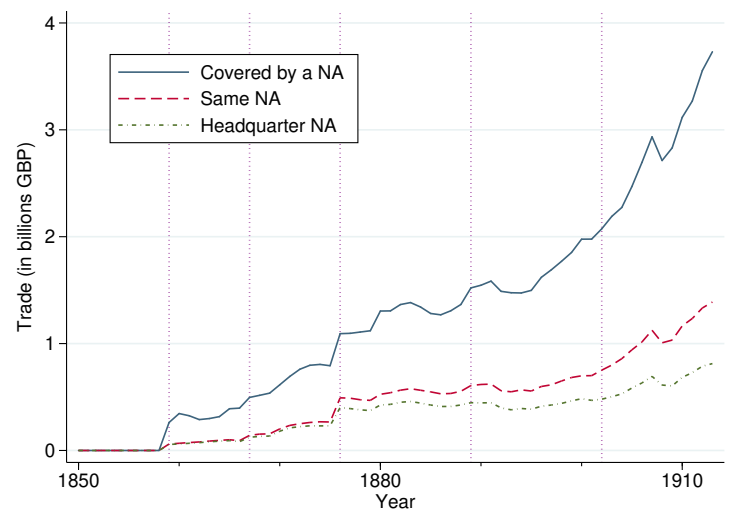

(b) Share of countries (in \%)

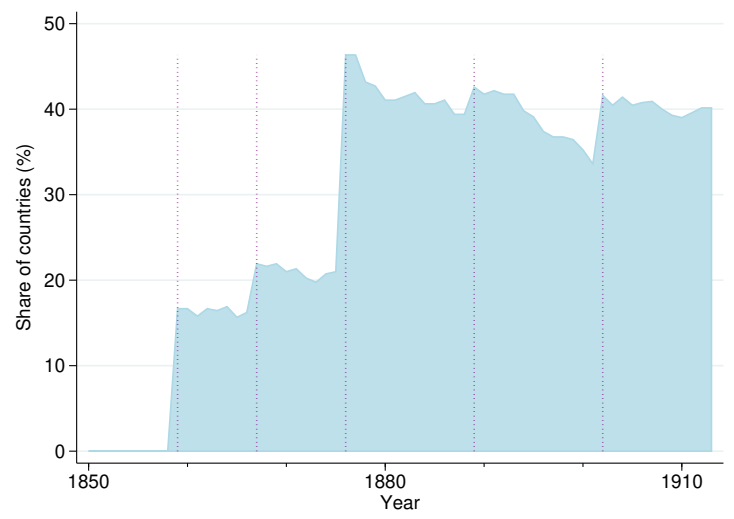

(d) Share of dyads (in \%)

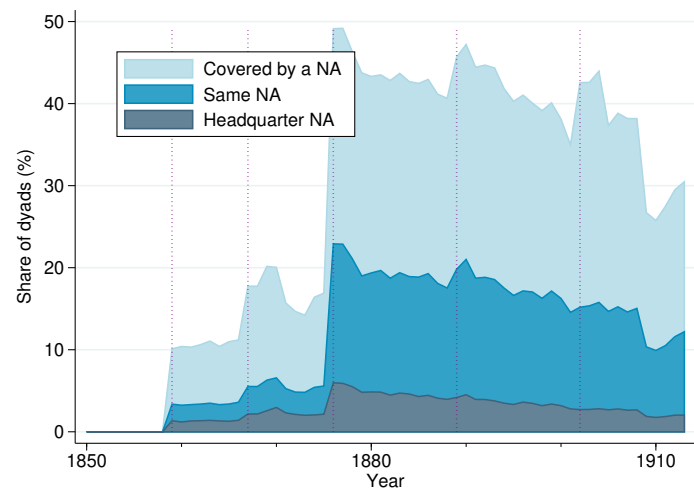

(f) Share of trade (in \%)

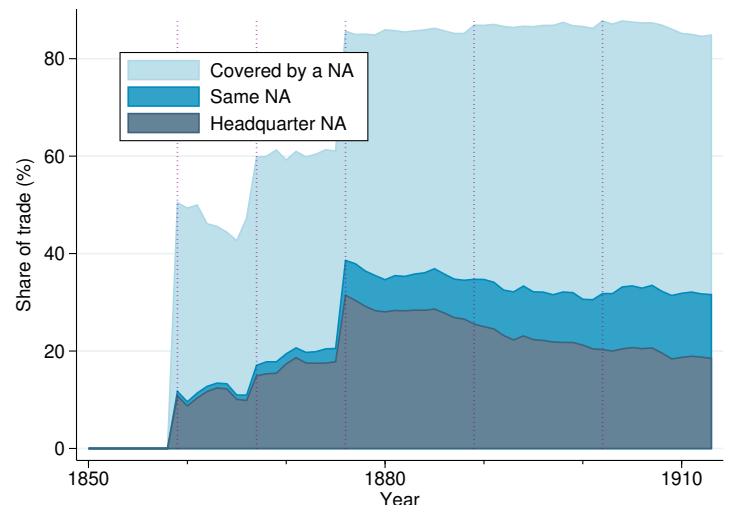

Note : Each vertical red line corresponds to an agreement extending the geographic coverage of the cartel. Only the countries (fig (a) and (b)) or the dyads (fig (c) and (d)) with non zero trade flows are counted. 
Figure 15: Evolution over time of telegraph and news agency coverage

(a) Number of countries

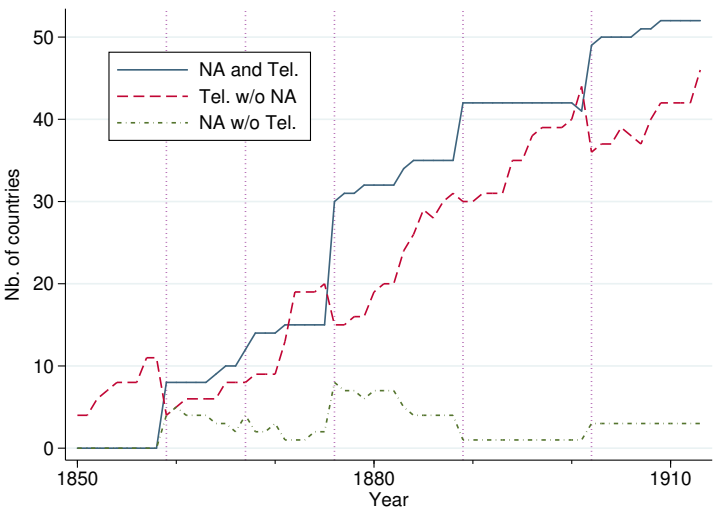

(c) Number of dyads

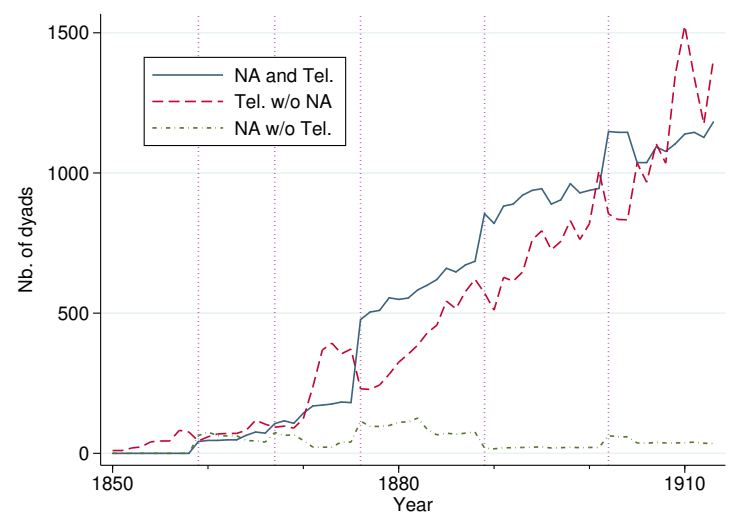

(e) Trade (in billions GBP)

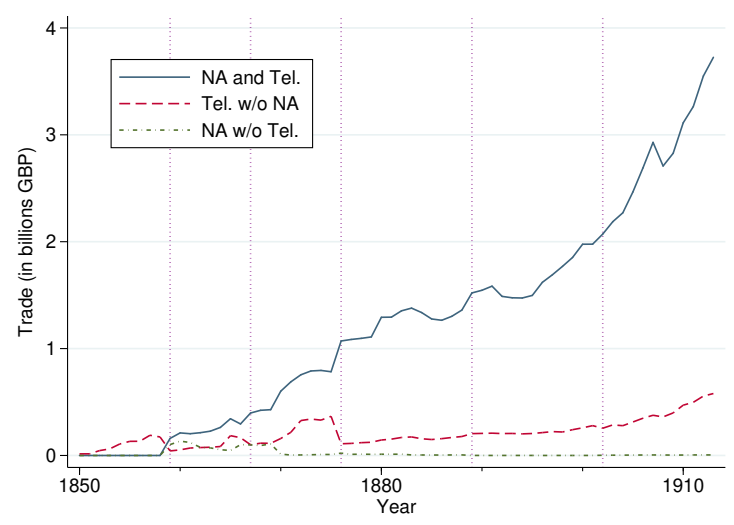

(b) Share of countries (in \%)

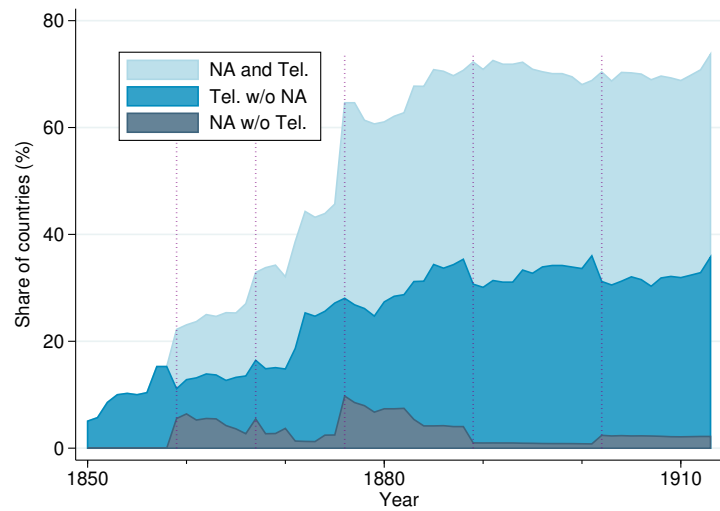

(d) Share of dyads (in \%)

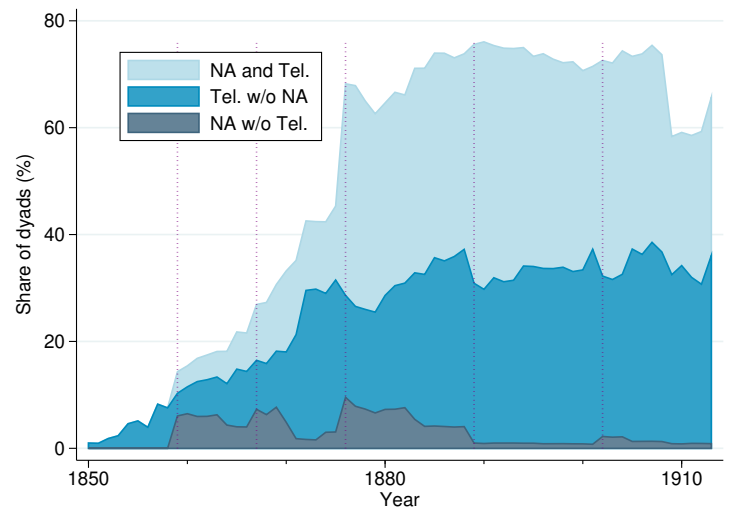

(f) Share of trade (in \%)

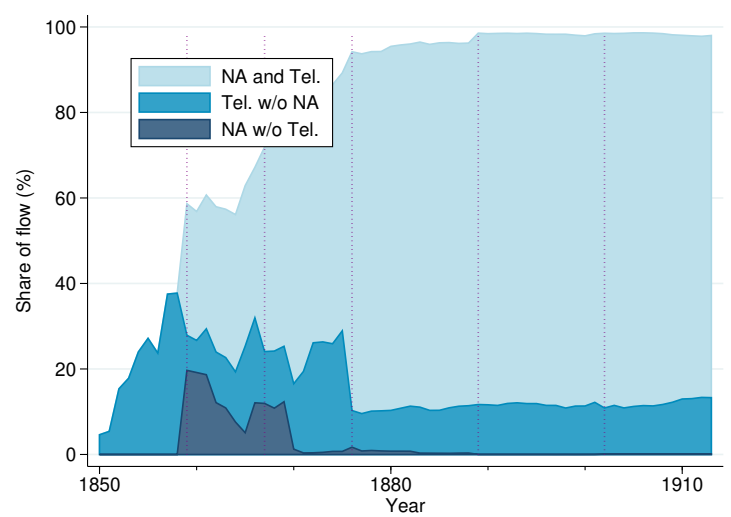

Note : "NA and Tel" refers to the observations that have a telegraph link and are covered by a global news agency. Each vertical red line corresponds to an agreement extending the geographic coverage of the cartel. 


\section{B Additional results}

\section{B.1 Panel Estimates}

Table 6: Effect of news agencies and telegraphs on trade flows, introducing each variable of interest separately.

\begin{tabular}{|c|c|c|c|c|}
\hline & $\begin{array}{c}(1) \\
S_{o d t}\end{array}$ & $\begin{array}{c}(2) \\
S_{o d t}\end{array}$ & $\begin{array}{c}(3) \\
S_{\text {odt }}\end{array}$ & $\begin{array}{c}(4) \\
S_{\text {odt }}\end{array}$ \\
\hline News Ag. $\times$ Tel. & $\begin{array}{c}0.556^{a} \\
{[0.120]}\end{array}$ & & & $\begin{array}{l}0.259^{c} \\
{[0.156]}\end{array}$ \\
\hline Telegraph & & $\begin{array}{c}0.448^{a} \\
{[0.112]}\end{array}$ & & $\begin{array}{c}0.334^{a} \\
{[0.115]}\end{array}$ \\
\hline News Agency & & & $\begin{array}{c}0.493^{a} \\
{[0.141]}\end{array}$ & $\begin{array}{l}0.222 \\
{[0.183]}\end{array}$ \\
\hline $\begin{array}{l}\text { Observations } \\
\text { Estimator } \\
\text { Sample } \\
\text { Colony controls }\end{array}$ & $\begin{array}{c}83373 \\
\text { PPML } \\
\text { Complete } \\
\square\end{array}$ & $\begin{array}{c}83373 \\
\text { PPML } \\
\text { Complete }\end{array}$ & $\begin{array}{c}83373 \\
\text { PPML } \\
\text { Complete }\end{array}$ & $\begin{array}{c}83373 \\
\text { PPML } \\
\text { Complete }\end{array}$ \\
\hline
\end{tabular}

Note: Data is aggregated at the country pair $\times$ year level. The dependent variable is the share of imports of destination $d$ coming from origin $o$. All specifications include destination $\times$ year, origin $\times$ year and country-pair fixed effects. All the dummy variables are mutually exclusive. In brackets are the standard errors, clustered by country-pair. Significance levels: ${ }^{a}: p<0.01 ;{ }^{b}: p<0.05 ;^{c}: p<0.1$. 
Table 7: Effect of news agencies and telegraphs on trade flows, mutually exclusive dummy variables (1850-1913).

\begin{tabular}{lcccccc}
\hline & $(1)$ & $(2)$ & $(3)$ & $(4)$ & $(5)$ & $(6)$ \\
& $\operatorname{Ln}\left(Y_{\text {odt }}\right)$ & $\operatorname{Ln}\left(Y_{\text {odt }}\right)$ & $S_{\text {odt }}$ & $S_{\text {odt }}$ & $S_{\text {odt }}>0$ & $S_{\text {odt }}$ \\
\hline \multirow{2}{*}{ News Ag. $\times$ Tel. } & $1.031^{a}$ & $1.037^{a}$ & $0.818^{a}$ & $0.815^{a}$ & $0.615^{a}$ & $0.778^{a}$ \\
& {$[0.214]$} & {$[0.214]$} & {$[0.175]$} & {$[0.175]$} & {$[0.127]$} & {$[0.216]$} \\
Telegraph & $0.319^{b}$ & $0.323^{b}$ & $0.323^{a}$ & $0.334^{a}$ & $0.181^{c}$ & $0.383^{a}$ \\
& {$[0.147]$} & {$[0.147]$} & {$[0.116]$} & {$[0.115]$} & {$[0.096]$} & {$[0.146]$} \\
News Agency & 0.286 & 0.287 & 0.232 & 0.222 & 0.178 & 0.075 \\
& {$[0.210]$} & {$[0.210]$} & {$[0.184]$} & {$[0.183]$} & {$[0.137]$} & {$[0.237]$} \\
Observations & 59910 & 59910 & 83373 & 83373 & 59910 & 140506 \\
Estimator & OLS & OLS & PPML & PPML & PPML & PPML \\
Sample & Complete & Complete & Complete & Complete & Complete & Balanced \\
Colony controls & & $\checkmark$ & & $\checkmark$ & $\checkmark$ & $\checkmark$ \\
\hline
\end{tabular}

Note: Data is aggregated at the country pair $\times$ year level. The dependent variable is the log of the bilateral trade flow in columns (1) and (2), and the share of imports of destination $d$ coming from origin $o$ in the remaining columns, (3) to (6). All specifications include destination $\times$ year, origin $\times$ year and country-pair fixed effects. All the dummy variables are mutually exclusive. In brackets are the standard errors, clustered by country-pair. Significance levels: ${ }^{a}: p<0.01 ;^{b}: p<0.05 ;^{c}: p<0.1$.

\section{B.2 Event-Study}

Figure 16: Additional Results of the Event-Study

(a) With dyad-specific time trends

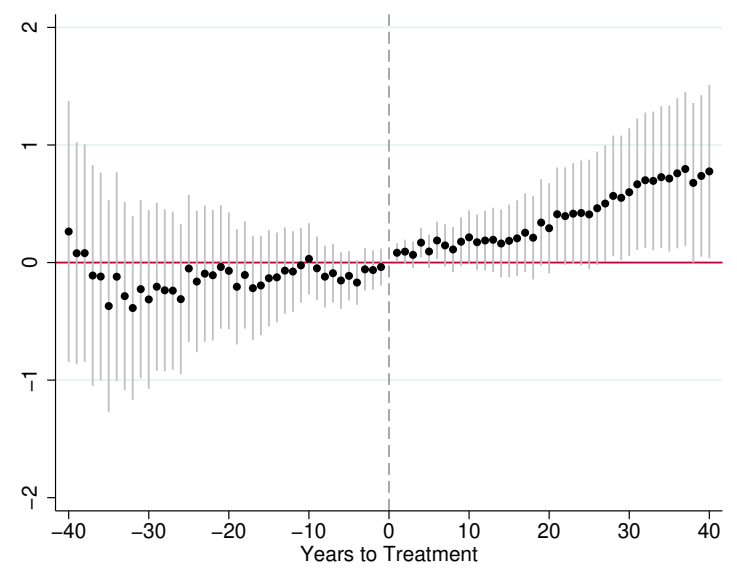

(b) Without the pre-treatment dummies

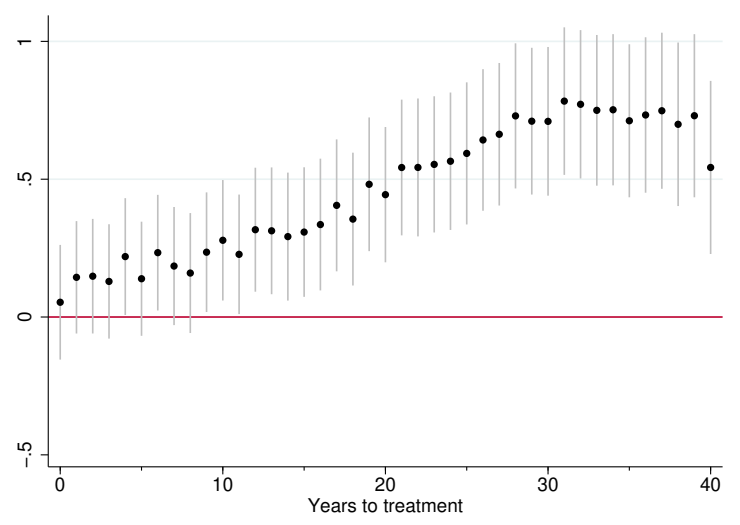

Notes: Spikes indicate the $95 \%$ confidence interval. 


\section{B.3 Cross-sectional Estimates}

Table 8: Cross-dyads correlation between tariffs and our variables of interest

\begin{tabular}{lcccc}
\hline & \multicolumn{4}{c}{ Average Tariff $_{\text {odt }}$} \\
\cline { 2 - 5 } & $(1)$ & $(2)$ & $(3)$ & $(4)$ \\
\hline News Ag. $\times$ Tel. & & & & \\
& -3.775 & -3.681 & 5.854 & 5.294 \\
News Ag. $\times$ Direct Tel. & {$[8.672]$} & {$[8.710]$} & {$[5.020]$} & {$[5.213]$} \\
& & 2.864 & & 6.216 \\
Headquarter News Ag. $\times$ Tel. & & {$[4.400]$} & & {$[4.299]$} \\
& & & -18.235 & -15.502 \\
Headquarter News Ag. $\times$ Direct Tel. & & & {$[11.758]$} & {$[11.519]$} \\
& & & & -9.565 \\
Telegraph & $-11.829^{b}$ & $-10.850^{b}$ & $-11.937^{b}$ & $-10.856^{b}$ \\
& {$[4.684]$} & {$[5.028]$} & {$[4.709]$} & {$[5.057]$} \\
Direct Tel. & & -6.928 & & -7.100 \\
& & {$[4.299]$} & & {$[4.313]$} \\
News Agency & -0.342 & -0.146 & $-12.486^{b}$ & $-12.256^{b}$ \\
Headquarter News Ag. & {$[9.270]$} & {$[9.304]$} & {$[4.868]$} & {$[4.874]$} \\
& & & $25.410^{c}$ & $25.452^{c}$ \\
Observations & & & {$[13.162]$} & {$[13.271]$} \\
Dyad FE & & & & \\
Year FE & 4436 & 4436 & 4436 & 4436 \\
\hline
\end{tabular}

Note: Data is aggregated at the country pair $\times$ year level. The dependent variable is the average tariff rate. All specifications include year fixed effects. In brackets are robust standard-errors. Significance levels: ${ }^{a}: p<0.01 ;^{b}: p<0.05 ;^{c}: p<0.1$. 
Figure 17: Evolution over time of cross-sectional gravity estimates

(a) Both countries colonized

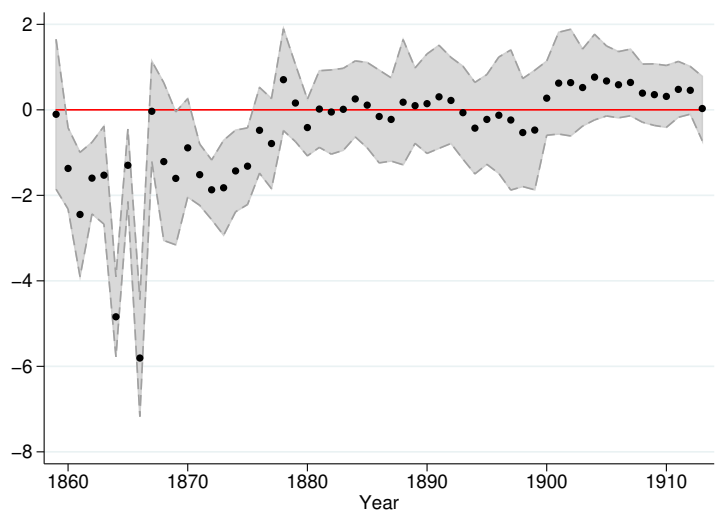

(c) Metropole-colony

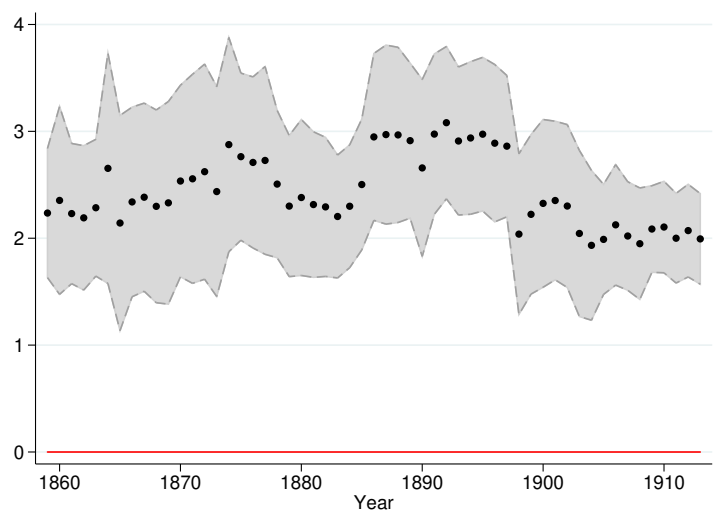

(b) Same colonizer

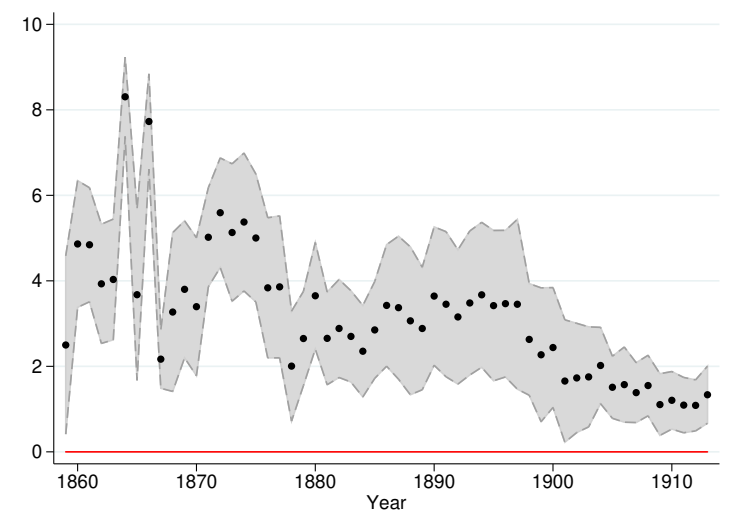

(d) Log of geographic distance

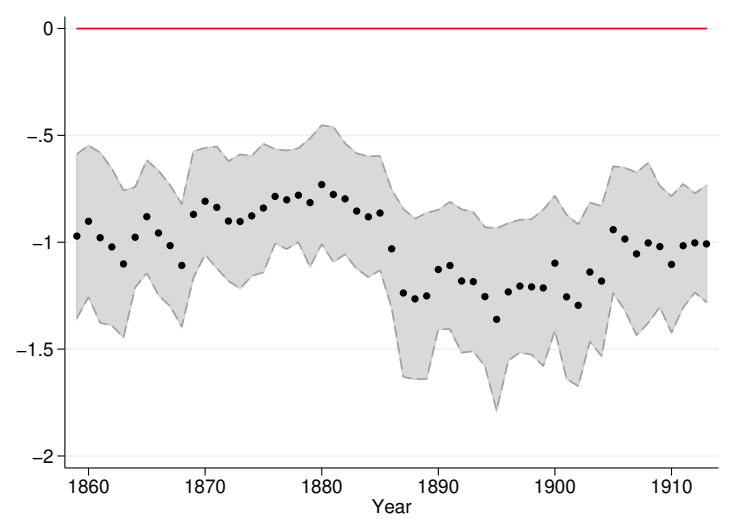

Notes: Each dot corresponds to a PPML estimate from a cross-sectional gravity equation, with trade shares as dependent variable, and with origin and destination fixed effects. 